\title{
Registered report: A coding-independent function of gene and pseudogene mRNAs regulates tumour biology
}

\author{
Israr Khan', John Kerwin², Kate Owen³ , Erin Griner ${ }^{3}$, Reproducibility Project: \\ Cancer Biology*
}
${ }^{1}$ Alamo Laboratories Inc, San Antonio, Texas; ${ }^{2}$ Biotechnology Research and Education Program, University of Maryland, College Park, Maryland; ${ }^{3}$ University of Virginia, Charlottesville, Virginia

\section{REPRODUCIBILITY CANCERECT-} CANCER BIOLOGY

*For correspondence: tim@ cos.io

Group author details

Reproducibility Project: Cancer

Biology

See page 26

Competing interests:

See page 26

Funding: See page 26

Received: 21 April 2015

Accepted: 08 August 2015

Published: 03 September 2015

Reviewing editor: Roger Davis, Howard Hughes Medical Institute \& University of Massachusetts Medical School, United States

cc) Copyright Khan et al. This article is distributed under the terms of the Creative Commons Attribution License, which permits unrestricted use and redistribution provided that the original author and source are credited.
Abstract The Reproducibility Project: Cancer Biology seeks to address growing concerns about reproducibility in scientific research by conducting replications of selected experiments from a number of high-profile papers in the field of cancer biology. The papers, which were published between 2010 and 2012, were selected on the basis of citations and Altmetric scores (Errington et al., 2014). This Registered report describes the proposed replication plan of key experiments from 'A coding-independent function of gene and pseudogene mRNAs regulates tumour biology' by Poliseno et al. (2010), published in Nature in 2010. The key experiments to be replicated are reported in Figures 1D, 2F-H, and 4A. In these experiments, Poliseno and colleagues report microRNAs miR-19b and miR-20a transcriptionally suppress both PTEN and PTENP1 in prostate cancer cells (Figure 1D; Poliseno et alo, 2010). Decreased expression of PTEN and/or PTENP1 resulted in downregulated PTEN protein levels (Figure 2H), downregulation of both mRNAs (Figure 2G), and increased tumor cell proliferation (Figure 2F; Poliseno et al., 2010). Furthermore, overexpression of the PTEN 3' UTR enhanced PTENP1 mRNA abundance limiting tumor cell proliferation, providing additional evidence for the co-regulation of PTEN and PTENP1 (Figure 4A; Poliseno et alo, 2010). The Reproducibility Project: Cancer Biology is collaboration between the Center for Open Science and Science Exchange, and the results of the replications will be published in elife.

DOI: 10.7554/eLife.08245.001

\section{Introduction}

The phosphatase and tensin homolog gene (PTEN) functions as a negative repressor of the PI3K/Akt survival pathway and is one of the most frequently deleted tumor suppressor genes in human cancer (Stambolic et alo, 1998; Song et al., 2012). As a regulator of PI3K signaling, loss of PTEN results in over-activation of Akt, leading to unchecked cell proliferation, reduced apoptosis, and elevated tumor angiogenesis (Stambolic et al., 1998; Carracedo et al., 2008). In prostate cancer, decreases in PTEN protein expression, either by allelic deletion or functional loss caused by mutation and/or epigenetic modification, can lead to invasive prostate carcinoma (Trotman et alo, 2003; Phin et alo, 2013). In preclinical systems, the genetic restoration of PTEN induces apoptosis in cancer cell lines and has a significant negative effect on tumor growth in multiple in vivo models (Li et al., 1998; Lu et al., 1999; Tian et al., 1999; Chen et alo, 2011). In contrast, clinical efforts to restore PTEN functionality have instead focused on targeting kinases in the PI3K pathway, including PI3K, Akt, and the mammalian target of rapamycin (Hopkins and Parsons, 2014). However, the development of PI3K targeting drugs has been complicated by the limited tolerability of current pharmacological treatments as well as tumor heterogeneity (Gerlinger et al., 2012; Bauer et al., 2014).

It is increasingly apparent that a complex regulatory network exists between the diverse RNA species pervasive in the human transcriptome. MicroRNAs (miRNAs) are small non-coding RNAs that bind to 
complementary sequences in the $3^{\prime}$ untranslated regions (UTR) of target messenger RNAs (mRNA), resulting in transcriptional downregulation of the target gene (Sen et al., 2014). Meng and colleagues showed that PTEN was repressed by miR-21, one of the most frequently upregulated miRNAs in cancer, in hepatocarcinoma cells, suggesting that the oncogenic potential of miR-21 occurs via the downregulation of PTEN expression (Chan et alo, 2005; Meng et al., 2006; Volinia et al., 2006; Meng et alo, 2007; Si et alı, 2007). Several miRNAs that target PTEN have since been reported (Jackson et al., 2014; Wang et al., 2015). While miRNAs play a functional role in silencing target gene expression, it is proposed that miRNAs themselves are subject to regulation by competing endogenous RNA (ceRNA) species, including pseudogenes, long non-coding RNAs, and circular RNAs (Salmena et alo, 2011; Cesana and Daley, 2013). In plants, for example, the non-protein coding gene IPS1 sequesters miRNAs away from their mRNA targets, thereby leading to an accumulation of target transcripts (Franco-Zorrilla et al., 2007). Poliseno and colleagues proposed that pseudogenes, which are non-coding genomic DNA sequences closely related to parental genes, can modulate parental gene expression by influencing the available levels of miRNAs within a cell (Poliseno et al., 2010; Cesana and Daley, 2013). However, the extent and manner that ceRNAs can exert a consequential effect on the repression of targets for that miRNA is currently unclear (Broderick and Zamore, 2014). Recently, Denzler and colleagues analyzed the stoichiometric relationship of miR-122 and target sites in adult mouse liver and reported that the natural abundance of target sites exceeded miRNAs, making the ceRNA hypothesis unlikely (Denzler et al., 2014).

PTENP1 is a pseudogene that shares close homology with PTEN, including the ability to bind miRNAs (Fujii et alo, 1999). To determine whether PTEN and PTENP1 expression levels are modulated by miRNA activity, Poliseno and colleagues first established that the PTEN-targeting miRNAs miR-19b and miR-20a were able to target both PTEN and PTENP1 (Poliseno et al., 2010). As reported in Figure 1D, overexpression of miR-19b and miR-20a in prostate cancer cells resulted in a significant decrease in PTEN and PTENP1 mRNA transcription. This is supported by additional studies demonstrating that overexpression of either miR-19b or miR-20a in cancer cell lines resulted in reduced PTEN mRNA levels and protein expression (Luo et al., 2013; Tian et al., 2013; Wu et al., 2014). The ability of miR-19b and miR-20a to target PTEN in prostate cancer was further confirmed by Tay et al. (2011). These key findings established that PTEN and PTENP1 are regulated by interactions with miRNA in multiple cancer cell types and will be replicated in Protocol 1.

In Figure 2F-H, Poliseno and colleagues tested the phenotypic consequences of PTENP1 downregulation by specifically targeting PTEN and/or PTENP1 expression. Downregulation of PTENP1 in DU145 prostate cancer cells resulted in a significant decrease in both PTEN and PTENP1 mRNA levels and protein expression (Figure 2G-H; Poliseno et alo, 2010). Furthermore, downregulation of PTENP1 profoundly accelerated the proliferation of DU145 cells (Figure 2F), with silencing of both PTEN and PTENP1 having an additive effect (Poliseno et alo, 2010). These experiments will be replicated in Protocols 2, 3, and 4. Recently, Tay and colleagues reported that PTEN-ceRNAs, including CNOT6L and VAPA, phenocopied PTENP1 activity, as downregulation of these non-coding transcripts in prostate and colon cancer cells were also able to modulate PTEN expression, Akt activity, and cell growth (Tay et alo, 2011). Additionally, other PTEN-ceRNAs that regulate PTEN expression have been reported in brain, breast, and skin cancers (Lee et alo, 2010; Karreth et alo, 2011; Sumazin et alo, 2011). Further to this, PTENP1 antisense RNA has been reported to regulate PTEN transcription and mRNA stability, suggesting a model where the PTENP1 pseudogene has biomodal functionality modulating PTEN (Johnsson et alo, 2013).

As an extension of the findings reported in Figure 2 and further genomic analysis, Poliseno and colleagues demonstrated that the PTEN 3' UTR regulates pseudogene expression, since overexpression of the PTEN 3' UTR was found to de-repress PTENP1 expression and inhibited DU145 proliferation (Figure 4A) (Poliseno et al., 2010). These experiments will be replicated in Protocols 5 and 6. These results were also confirmed by experiments by $Y u$ and colleagues showing that overexpression of either PTEN or PTENP1 suppressed renal cancer cell proliferation (Yu et al., 2014). Further to this, the oncosuppressive properties of overexpressing PTENP1 3' UTR have been reported in various cancer cells (Poliseno et al., 2010; Chen et al., 2015; Guo et al., 2015).

\section{Materials and methods}

\section{Protocol 1: Quantitative PCR after miR transfection}

This experiment utilizes quantitative RT-PCR to analyze the effect of miR-19b or miR-20a on the mRNA levels of PTEN and PTENP1. It is a replication of Figure 1D. 


\section{Sampling}

- Experiment to be repeated a total of six times for a minimum power of $88 \%$. O See 'Power calculations' section for details.

- Experiment has 5 conditions:

O Cohort 1: siGENOME non-targeting siRNA \#2 (siLUC) transfected DU145 cells.

Cohort 2: miR-19b transfected DU145 cells.

O Cohort 3: miR-20a transfected DU145 cells.

O Cohort 4: Untransfected DU145 cells (additional negative control).

O Transfection control: siGLO RISC-free siRNA transfected DU145 cells.

- Quantitative RT-PCR performed in technical triplicate for the following genes:

O PTEN.

O PTENP1.

O ACTIN (internal control).

O 36B4 (additional internal control).

\section{Materials and reagents}

\begin{tabular}{|c|c|c|c|c|}
\hline Reagent & Type & Manufacturer & Catalog \# & Comments \\
\hline DU145 cells & Cell line & ATCC & HTB-81 & - \\
\hline RPMI 1640 medium & Cell culture & Sigma-Aldrich & R8758 & Replaces Invitrogen brand used in original study \\
\hline Fetal bovine serum (FBS) & Cell culture & Sigma-Aldrich & F2442 & Replaces Invitrogen brand used in original study \\
\hline L-glutamine & Cell culture & Sigma-Aldrich & G7513 & Original brand not specified \\
\hline 100x Penicillin/streptomycin & Cell culture & Sigma-Aldrich & P4333 & Original brand not specified \\
\hline 0.05\% trypsin/0.48 mM EDTA & Cell culture & Sigma-Aldrich & T3924 & Original brand not specified \\
\hline $\begin{array}{l}\text { Phosphate buffered saline (PBS), without } \\
\mathrm{MgCl}_{2} \text { and } \mathrm{CaCl}_{2}\end{array}$ & Cell culture & Sigma-Aldrich & D8537 & Original brand not specified \\
\hline 12 well tissue culture dishes & Labware & Corning & 3513 & Original brand not specified \\
\hline siGLO RISC-free siRNA & Nucleic acid & Dharmacon & D-001600-01 & - \\
\hline $\begin{array}{l}\text { siGENOME non-targeting siRNA \#2 } \\
\text { (siLUC) }\end{array}$ & Nucleic acid & Dharmacon & D-001210-02 & - \\
\hline $\begin{array}{l}\text { miRIDIAN microRNA hsa-miR-19b-3p (si- } \\
\text { miR-19b) }\end{array}$ & Nucleic acid & Dharmacon & IH-300489-05-0002 & - \\
\hline $\begin{array}{l}\text { miRIDIAN microRNA hsa-miR-20a-5p (si- } \\
\text { miR20a) }\end{array}$ & Nucleic acid & Dharmacon & IH-300491-05-0002 & - \\
\hline Dharmafect 1 & Cell culture & Dharmacon & T-2001-01 & - \\
\hline PTENP1 forward and reverse primers & Nucleic acid & \multirow{4}{*}{\multicolumn{3}{|c|}{$\begin{array}{l}\text { Specific brand information will be left up to the discretion of the replicating lab and recorded } \\
\text { later }\end{array}$}} \\
\hline PTEN forward and reverse primers & Nucleic acid & & & \\
\hline ACTIN forward and reverse primers & Nucleic acid & & & \\
\hline 36B4 forward and reverse primers & Nucleic acid & & & \\
\hline TRI reagent & Chemical & Sigma-Aldrich & T9424 & Replaces Trizol reagent from Invitrogen \\
\hline 1-bromo-3-chloropropase & Chemical & Sigma-Aldrich & B9673 & Reagent needed from TRI reagent protocol \\
\hline Nuclease free water & Chemical & Sigma-Aldrich & W4502 & Reagent needed from TRI reagent protocol \\
\hline Microscope & Instrument & Zeiss & - & Original brand not specified \\
\hline Axiovision & Software & Zeiss & - & Original brand not specified \\
\hline DNAse I amplification grade & Chemical & Sigma-Aldrich & AMPD1 & Replaces Invitrogen brand used in original study \\
\hline $\begin{array}{l}\text { First-strand cDNA synthesis kit (includes } \\
\text { pd(N)6 random hexamers and Notl-(dT) } \\
18 \text { primers) }\end{array}$ & Kit & Sigma-Aldrich & GE27-9261-01 & $\begin{array}{l}\text { Replaces SuperScript II reverse transcriptase from } \\
\text { Invitrogen used in original study }\end{array}$ \\
\hline QuantiTect Sybr Green PCR kit & Kit & Qiagen & 204141 & - \\
\hline $\begin{array}{l}\text { Real Time System with a C1000 Thermal } \\
\text { Cycler }\end{array}$ & Instrument & BioRad & CFX 96 & $\begin{array}{l}\text { Replaces Roche Lightcycler } 2.0 \text { used in original } \\
\text { study }\end{array}$ \\
\hline
\end{tabular}




\section{Procedure}

Notes

- Cells will be sent for mycoplasma testing and short tandem repeat (STR) profiling.

- DU145 cells are grown in complete RPMI 1640 supplemented with 2 mM glutamine, 10\% FBS, 100 $\mathrm{U} / \mathrm{ml}$ penicillin and $100 \mu \mathrm{g} / \mathrm{ml}$ streptomycin at $37^{\circ} \mathrm{C}$ and $6 \% \mathrm{CO}_{2}$.

1. Seed $1.5 \times 10^{5}$ DU145 cells per well in a 12 -well dish. Grow overnight.

2. Transfect with $100 \mathrm{nM}$ siLuc, si-miR-19b, and si-miR-20a using $3 \mu$ of Dharmafect 1 according to manufacturer's instructions. Transfect control cells with siGLO RISC-free control siRNA following manufacturer's instructions. Include untransfected control cells. Grow overnight.

3. Confirm that $>90 \%$ of siGLO transfected control cells show fluorescence, indicating they were successfully transfected.

a. If transfection is less than $90 \%$, record efficiency for attempt, exclude attempt and do not continue with the rest of the procedure. Repeat procedure until $>90 \%$ efficiency is obtained.

b. If modification to transfection (step 2) is needed, record and maintain modified steps for remaining replicates.

4. $24 \mathrm{hr}$ after transfection, extract total RNA from cells directly on the culture dish using TRI reagent and 1-bromo-3-chloropropane according to manufacturer's instructions.

5. Treat RNA with DNAse I following manufacturer's instructions.

a. Record RNA concentration and purity $\left(A_{280} / A_{260}\right)$.

6. Reverse transcribe $1 \mu \mathrm{g}$ RNA/sample into cDNA using first-strand cDNA synthesis kit with primers following manufacturer's instructions.

7. Perform quantitative PCR reaction using the QuantiTect Sybr Green PCR kit:

a. Use $2 \mu \mathrm{l}$ of reverse transcription reaction per $20 \mu \mathrm{l}$ real-time PCR reaction.

b. Perform quantitative PCR for PTEN, PTENP1, ACTIN, and $36 B 4$.

i. PTEN forward primer: 5'-GTTTACCGGCAGCATCAAAT-3'

ii. PTEN reverse primer: 5'-CCCCCACTTTAGTGCACAGT-3'

iii. PTENP1 forward primer: 5'-TCAGAACATGGCATACACCAA-3'

iv. PTENP1 reverse primer: 5'-TGATGACGTCCGATTTTTCA-3'

v. ACTIN forward primer: 5'-CATGTACGTTGCTATCCAGGC-3'

vi. ACTIN reverse primer: 5'-CTCCTTAATGTCACGCACGAT-3'

vii. 36B4 forward primer: 5'-GTGTTCGACAATGGCAGCAT-3'

viii. 36B4 reverse primer: 5'-GACACCCTCCAGGAAGCGA-3'

i. $36 B 4$ primer sequences reported in Fullwood et al. (2009).

c. Do not pre-treat with uracil-N-glycosylase.

d. All reactions should be optimized and run in technical triplicate.

8. Using ACTIN as an internal standard, calculate the relative PTEN and PTENP1 expression for each sample using the comparative $\mathrm{Ct}$ method.

a. Additionally perform normalization using 36B4 as an internal standard (additional control).

9. Repeat independently five additional times.

\section{Deliverables}

- Data to be collected:

Images of fluorescence and phase/contrast of siGLO transfected cells.

Purity $\left(\mathrm{A}_{260 / 280}\right.$ ratio) and concentration of isolated total RNA from cells.

$O$ Raw data for all GPCR reactions.

O Quantification of PTEN and PTENP1 mRNA levels relative to ACTIN.

$O$ Quantification of fold change PTEN and PTENP1 mRNA levels relative to siLuc transfected cells. (Compare to Figure 1D).

Confirmatory analysis plan

This replication attempt will perform the statistical analysis listed below.

- Statistical Analysis:

Note: at the time of analysis, we will perform the Shapiro-Wilk test and generate a quantilequantile plot to assess the normality of the data. We will also perform Levene's test to assess homoscedasticity. If the data appear skewed we will perform the appropriate transformation in 
order to proceed with the proposed statistical analysis. If this is not possible we will perform the planned comparisons using the Wilcoxon-Mann Whitney test.

O One-way MANOVA of normalized PTEN or PTENP1 mRNA fold change in siLuc, 19b, or 20a siRNA transfected cells with the following planned comparisons using the Bonferroni correction:

1. PTEN mRNA levels of siLuc transfected cells compared to $19 \mathrm{~b}$ transfected cells.

2. PTEN mRNA levels of siLuc transfected cells compared to 20 a transfected cells.

3. PTENP1 mRNA levels of siLuc transfected cells compared to 19b transfected cells.

4. PTENP1 mRNA levels of siLuc transfected cells compared to 20a transfected cells.

- Meta-analysis of effect sizes:

O Compute the effect sizes of each comparison, compare them against the effect size in the original paper and use a random effects meta-analytic approach to combine the original and replication effects, which will be presented as a forest plot.

- Additional exploratory analysis:

The same analysis described above will be performed with $36 B 4$ normalized values, which serves as an independent normalization control not included in the original analysis.

Known differences from the original study

The PTEN and PTENP1 mRNA levels will be normalized with an independent control (36B4) in addition to ACTIN. All known differences are listed in the materials and reagents section above with the originally used item listed in the comments section. All differences have the same capabilities as the original and are not expected to alter the experimental design.

\section{Provisions for quality control}

The cell line used in this experiment will undergo STR profiling to confirm its identity and will be sent for mycoplasma testing to ensure there is no contamination. Transfection efficiency will be recorded for each replicate and any transfection that does not contain $>90 \%$ efficiency will be excluded and not continue through the rest of the procedure. If the efficiency in the first attempt(s) does not obtain $>90 \%$, then any modifications to the transfection protocol will be recorded and the procedure will be maintained for the remaining replicates. The sample purity $\left(\mathrm{A}_{260 / 280}\right.$ ratio) of the isolated RNA from each sample will be reported. The PTEN and PTENP1 mRNA levels will be normalized with an independent control (36B4). All the raw data, including the analysis files, will be uploaded to the project page on the Open Science Framework (OSF) (https://osf.io/yyqas) and made publically available.

\section{Protocol 2: Cell growth assay following siRNA transfection}

This experiment tests the effect of siRNA mediated depletion of PTEN, PTENP1, or both on the growth of DU145 cells. It is a replication of Figure 2F.

\section{Sampling}

- Experiment to be repeated a total of five times for a minimum power of $94 \%$. O See 'Power calculations' section for details.

- Experiment has 6 conditions:

O Cohort 1: siGENOME non-targeting siRNA \#2 (siLUC) transfected DU145 cells.

O Cohort 2: siPTEN Smartpool (targets PTEN and PTENP1) transfected DU145 cells.

O Cohort 3: siPTEN transfected DU145 cells.

O Cohort 4: siPTENP1 transfected DU145 cells.

O Cohort 5: Untransfected DU145 cells (additional negative control).

Transfection control: siGLO RISC-free siRNA transfected DU145 cells.

- Each cohort is harvested on the following days performed in technical triplicate:

$\mathrm{O}$ Day 0 (after $\mathrm{O} / \mathrm{N}$ incubation).

Day 1.

Day 2.

O Day 3.

O Day 4.

Day 5 . 


\section{Materials and reagents}

\begin{tabular}{|c|c|c|c|c|}
\hline Reagent & Type & Manufacturer & Catalog \# & Comments \\
\hline DU145 cells & Cell line & ATCC & HTB-81 & - \\
\hline RPMI 1640 medium & Cell culture & Sigma-Aldrich & R8758 & $\begin{array}{l}\text { Replaces Invitrogen brand used in } \\
\text { original study }\end{array}$ \\
\hline Fetal bovine serum (FBS) & Cell culture & Sigma-Aldrich & F2442 & $\begin{array}{l}\text { Replaces Invitrogen brand used in } \\
\text { original study }\end{array}$ \\
\hline L-glutamine & Cell culture & Sigma-Aldrich & G7513 & Original brand not specified \\
\hline 100x Penicillin/streptomycin & Cell culture & Sigma-Aldrich & P4333 & Original brand not specified \\
\hline 0.05\% trypsin/0.48 mM EDTA & Cell culture & Sigma-Aldrich & T3924 & Original brand not specified \\
\hline $\begin{array}{l}\text { Phosphate buffered saline (PBS), without } \\
\mathrm{MgCl}_{2} \text { and } \mathrm{CaCl}_{2}\end{array}$ & Cell culture & Sigma-Aldrich & D8537 & Original brand not specified \\
\hline 12 well tissue culture dishes & Labware & Corning & 3513 & Original brand not specified \\
\hline siGLO RISC-free siRNA & Nucleic acid & Dharmacon & D-001600-01 & - \\
\hline $\begin{array}{l}\text { siGENOME non-targeting siRNA \#2 } \\
\text { (siLUC) }\end{array}$ & Nucleic acid & Dharmacon & D-001210-02 & - \\
\hline siPTEN & Nucleic acid & Dharmacon & Custom & $\begin{array}{l}\text { See Supplemental Figure } 6 \text { of original } \\
\text { paper for sequence }\end{array}$ \\
\hline ON-TARGETplus siPTEN Smartpool & Nucleic acid & Dharmacon & L-003023-00 & $\begin{array}{l}\text { Composed of: J-003023-09; J-003023-10; } \\
\text { J-003023-11; J-003023-12 }\end{array}$ \\
\hline siPTENP1 & Nucleic acid & Dharmacon & Custom & $\begin{array}{l}\text { See Supplemental Figure } 6 \text { of original } \\
\text { paper for sequence }\end{array}$ \\
\hline Dharmafect 1 & Cell culture & Dharmacon & T-2001-01 & - \\
\hline Microscope & Instrument & Olympus & LX81 & Original brand not specified \\
\hline Crystal violet & Dye & Sigma-Aldrich & C0775 & Original brand not specified \\
\hline Formalin & Chemical & \multirow{3}{*}{\multicolumn{3}{|c|}{$\begin{array}{l}\text { Specific brand information will be left up to the discretion of the replicating lab and recorded } \\
\text { later }\end{array}$}} \\
\hline Acetic acid & Chemical & & & \\
\hline Methanol & Chemical & & & \\
\hline $\begin{array}{l}\text { Spectrophotometer capable of reading } \\
\text { at } 590 \mathrm{~nm} \text { (or } 595 \mathrm{~nm} \text { ) }\end{array}$ & Instrument & BioTek Instruments & Synergy 2 (SLFA configuration) & Original brand not specified \\
\hline
\end{tabular}

\section{Procedure}

Note

- All cells will be sent for mycoplasma testing and STR profiling.

- DU145 cells grown in complete RPMI 1640: RPMI 1640 supplemented with 2 mM glutamine, 10\% FBS, $100 \mathrm{U} / \mathrm{ml}$ penicillin and $100 \mu \mathrm{g} / \mathrm{ml}$ streptomycin at $37^{\circ} \mathrm{C}$ and $6 \% \mathrm{CO}_{2}$.

1. Seed $1.5 \times 10^{5}$ DU145 cells per well in a 12-well dish. Grow overnight.

2. Transfect with $100 \mathrm{nM}$ siRNAs (siPTEN, siPTENP1, siPTEN Smartpool (siPTEN and PTENP1), or siLuc in separate wells) using Dharmafect 1 according to manufacturer's instructions or leave untransfected. Transfect control cells with siGLO RISC-free control siRNA according to manufacturer's instructions. Grow overnight.

3. Confirm that $>90 \%$ of siGLO transfected control cells show fluorescence, indicating they were successfully transfected.

a. If transfection is less than $90 \%$, record efficiency for attempt, exclude attempt and do not continue with the rest of the procedure. Repeat procedure until $>90 \%$ efficiency is obtained.

b. If modification to transfection (step 2) is needed, record and maintain modified steps for remaining replicates.

4. The day after transfection, resuspend $2 \times 10^{5}$ siLuc, siPTEN, siPTENP1, siPTEN/PTENP1, or untransfected cells in $50 \mathrm{ml}$ fresh media. Seed three wells of six sets of 12-well plates with $2 \mathrm{ml}$ of each cell line. Each set of 12 well plates should have three wells of each cell line. Incubate overnight.

5. Fix one plate every $24 \mathrm{hr}$ starting after overnight incubation (the first plate fixed will be called day 0 ). a. Wash wells once in PBS. 
b. Fix wells with $10 \%$ formalin for $10 \mathrm{~min}$ at room temperature.

c. Store plates in PBS at $4^{\circ} \mathrm{C}$.

d. All wells should be fixed by day 6 .

6. Stain cells with $0.1 \%$ crystal violet, $20 \%$ methanol for $15 \mathrm{~min}$. Wash cells.

7. Lyse all wells with $10 \%$ acetic acid for $10 \mathrm{~min}$.

8. Read optical density at 590 or $595 \mathrm{~nm}$.

a. Reading can be done at $595 \mathrm{~nm}$ if 590 is not available.

9. Repeat independently four additional times.

\section{Deliverables}

- Data to be collected:

Images of fluorescence and phase/contrast of siGLO transfected cells.

Raw data of absorbance from plate reader.

$\bigcirc$ Graph of relative cell number for each cell line over time. (Compare to Figure 2F).

\section{Confirmatory analysis plan}

This replication attempt will perform the following statistical analysis listed below.

- Statistical Analysis:

Note: at the time of analysis, we will perform the Shapiro-Wilk test and generate a quantilequantile plot to assess the normality of the data. We will also perform Levene's test to assess homoscedasticity. If the data appear skewed we will perform the appropriate transformation in order to proceed with the proposed statistical analysis. If this is not possible we will perform the equivalent non-parametric test.

O Two-way ANOVA comparing Day 5 absorbance in siLuc, siPTEN, siPTENP1, or siPTEN/PTENP1 transfected cells with the following planned comparisons using the Bonferroni correction:

1. siluc compared to siPTEN.

2. siLuc compared to siPTENP1.

3. siLuc compared to siPTEN/PTENP1.

4. siPTEN/PTENP1 compared to siPTEN.

5. siPTEN/PTENP1 compared to siPTENP1.

Two-way ANOVA comparing area under the curve (AUC) measurements (determined from day 0 , $1,2,3,4$, and 5 for each replicate) from absorbance in siLuc, siPTEN, siPTENP1, or siPTEN/ PTENP1 transfected cells with the following planned comparisons using the Bonferroni correction.

1. siluc compared to siPTEN.

2. siLuc compared to siPTENP1.

3. siLuc compared to siPTEN/PTENP1.

4. siPTEN/PTENP1 compared to siPTEN.

5. siPTEN/PTENP1 compared to siPTENP1.

- Meta-analysis of effect sizes:

Compute the effect sizes of each comparison, compare them against the effect size in the original paper and use a random effects meta-analytic approach to combine the original and replication effects, which will be presented as a forest plot.

Known differences from the original study

All known differences are listed in the materials and reagents section above with the originally used item listed in the comments section. All differences have the same capabilities as the original and are not expected to alter the experimental design.

Provisions for quality control

The cell line used in this experiment will undergo STR profiling to confirm its identity and will be sent for mycoplasma testing to ensure there is no contamination. Transfection efficiency will be recorded for each replicate and any transfection that does not contain $>90 \%$ efficiency will be excluded and not continue through the rest of the procedure. If the efficiency in the first attempt(s) does not obtain $>90 \%$, then any modifications to the transfection protocol will be recorded and the procedure will be maintained for the remaining replicates. All the raw data, including the analysis files, will be uploaded to the project page on the OSF (https://osf.io/yyqas) and made publically available. 


\section{Protocol 3: Quantitative PCR following transfected with siRNA against PTEN and/or PTENP1}

This experiment analyzes the effect of depletion of PTEN, PTENP1, or both on the mRNA expression of PTEN or PTENP1. Quantitative real time PCR is utilized to assess the levels of expression following transfection of siRNA. This protocol is a replication of Figure 2G.

Sampling

- Experiment to be repeated a total of five times for a minimum power of $89 \%$. O See 'Power calculations' section for details.

- Experiment has 6 conditons:

O Cohort 1: Uninfected DU145 cells (additional negative control).

O Cohort 1: siGENOME non-targeting siRNA \#2 (siLUC) transfected DU145 cells.

O Cohort 2: siPTEN Smartpool (targets PTEN and PTENP1) transfected DU145 cells.

Cohort 3: siPTEN transfected DU145 cells.

O Cohort 4: siPTENP1 transfected DU145 cells.

O Cohort 5: Uninfected DU145 cells (additional negative control).

O Transfection control: siGLO RISC-free siRNA transfected DU145 cells.

- Quantitative RT-PCR performed in technical triplicate for the following genes:

O PTEN.

O PTEN1P.

O ACTIN (internal control).

36B4 (additional internal control).

Materials and reagents

\begin{tabular}{|c|c|c|c|c|}
\hline Reagent & Type & Manufacturer & Catalog \# & Comments \\
\hline DU145 cells & Cell line & ATCC & HTB-81 & - \\
\hline RPMI 1640 medium & Cell culture & Sigma-Aldrich & R8758 & Replaces Invitrogen brand used in original study \\
\hline Fetal bovine serum (FBS) & Cell culture & Sigma-Aldrich & F2442 & Replaces Invitrogen brand used in original study \\
\hline L-glutamine & Cell culture & Sigma-Aldrich & G7513 & Original brand not specified \\
\hline 100x Penicillin/streptomycin & Cell culture & Sigma-Aldrich & P4333 & Original brand not specified \\
\hline 0.05\% trypsin/0.48 mM EDTA & Cell culture & Sigma-Aldrich & T3924 & Original brand not specified \\
\hline $\begin{array}{l}\text { Phosphate buffered saline (PBS), without } \\
\mathrm{MgCl}_{2} \text { and } \mathrm{CaCl}_{2}\end{array}$ & Cell culture & Sigma-Aldrich & D8537 & Original brand not specified \\
\hline 12 well tissue culture dishes & Labware & Corning & 3513 & Original brand not specified \\
\hline siGLO RISC-free siRNA & Nucleic acid & Dharmacon & D-001600-01 & - \\
\hline $\begin{array}{l}\text { siGENOME non-targeting siRNA \#2 } \\
\text { (siLUC) }\end{array}$ & Nucleic acid & Dharmacon & D-001210-02 & - \\
\hline ON-TARGETplus siPTEN Smartpool & Nucleic acid & Dharmacon & L-003023-00 & $\begin{array}{l}\text { Composed of: J-003023-09; J-003023-10; } \\
\text { J-003023-11; J-003023-12 }\end{array}$ \\
\hline siPTEN & Nucleic acid & Dharmacon & Custom & $\begin{array}{l}\text { See Supplemental Figure } 6 \text { of original paper for } \\
\text { sequence }\end{array}$ \\
\hline siPTENP1 & Nucleic acid & Dharmacon & Custom & $\begin{array}{l}\text { See Supplemental Figure } 6 \text { of original paper for } \\
\text { sequence }\end{array}$ \\
\hline Dharmafect 1 & Cell culture & Dharmacon & T-2001-01 & - \\
\hline Microscope & Instrument & Olympus & LX81 & Original brand not specified \\
\hline ACTIN forward and reverse primers & Nucleic acid & \multirow{4}{*}{\multicolumn{3}{|c|}{$\begin{array}{l}\text { Specific brand information will be left up to the discretion of the replicating lab and recorded } \\
\text { later }\end{array}$}} \\
\hline PTEN forward and reverse primers & Nucleic acid & & & \\
\hline PTENP1 forward and reverse primers & Nucleic acid & & & \\
\hline 36B4 forward and reverse primers & Nucleic acid & & & \\
\hline TRI reagent & Chemical & Sigma-Aldrich & T9424 & Replaces Trizol reagent from Invitrogen \\
\hline 1-bromo-3-chloropropase & Chemical & Sigma-Aldrich & B9673 & Reagent needed from TRI reagent protocol \\
\hline
\end{tabular}

Continued on next page 
Continued

\begin{tabular}{|c|c|c|c|c|}
\hline Reagent & Type & Manufacturer & Catalog \# & Comments \\
\hline Nuclease free water & Chemical & Sigma-Aldrich & W4502 & Reagent needed from TRI reagent protocol \\
\hline DNase I amplification grade & Chemical & Sigma-Aldrich & AMPD1 & Replaces Invitrogen brand used in original study \\
\hline $\begin{array}{l}\text { First-strand cDNA synthesis kit (includes } \\
\text { pd(N)6 random hexamers and Notl-(dT) } \\
18 \text { primers) }\end{array}$ & Kit & Sigma-Aldrich & GE27-9261-01 & $\begin{array}{l}\text { Replaces SuperScript II reverse transcriptase from } \\
\text { Invitrogen used in original study }\end{array}$ \\
\hline QuantiTect Sybr Green PCR kit & Kit & Qiagen & 204141 & - \\
\hline Real-time PCR machine & Instrument & Applied Biosystems & 7500 & $\begin{array}{l}\text { Replaces Lightcycler } 2.0 \text { from Roche used in } \\
\text { original study }\end{array}$ \\
\hline
\end{tabular}

Procedure

Note

- All cells will be sent for mycoplasma testing and STR profiling.

- DU145 cells grown in complete RPMI 1640: RPMI 1640 supplemented with 2 mM glutamine, 10\% FBS, $100 \mathrm{U} / \mathrm{ml}$ penicillin and $100 \mu \mathrm{g} / \mathrm{ml}$ streptomycin at $37^{\circ} \mathrm{C}$ and $6 \% \mathrm{CO}_{2}$.

1. Seed $1.5 \times 10^{5}$ DU145 cells per well in a 12-well dish. Grow overnight.

2. Transfect with $100 \mathrm{nM}$ siRNAs (siPTEN, siPTENP1, siPTEN Smartpool (siPTEN/PTENP1), or siLuc in separate wells) using Dharmafect 1 according to manufacturer's instructions or leave untransfected. Transfect control cells with siGLO RISC-free control siRNA according to manufacturer's instructions. Grow overnight.

3. Confirm that $>90 \%$ of siGLO transfected control cells show fluorescence, indicating they were successfully transfected.

a. If transfection is less than $90 \%$, record efficiency for attempt, exclude attempt and do not continue with the rest of the procedure. Repeat procedure until $>90 \%$ efficiency is obtained.

b. If modification to transfection (step 2) is needed, record and maintain modified steps for remaining replicates.

4. $24 \mathrm{hr}$ after transfection, extract total RNA directly on the culture dish using TRI reagent and 1bromo-3-chloropropane according to manufacturer's instructions.

5. Treat RNA with DNAse following manufacturer's instructions.

6. Reverse transcribe $1 \mu \mathrm{g}$ RNA/sample into cDNA using first-strand cDNA synthesis kit with primers following manufacturer's instructions.

a. Record RNA concentration and purity $\left(A_{280} / A_{260}\right)$.

7. Perform quantitative PCR reaction using the QuantiTect Sybr Green PCR kit:

a. Use $2 \mu \mathrm{l}$ of reverse transcription reaction per $20 \mu \mathrm{l}$ real-time PCR reaction.

b. Perform quantitative PCR for PTEN, PTENP1, ACTIN, and 36B4.

i. PTEN forward primer: 5'-GTTTACCGGCAGCATCAAAT-3'

ii. PTEN reverse primer: 5'-CCCCCACTTTAGTGCACAGT-3'

iii. PTENP1 forward primer: 5'-TCAGAACATGGCATACACCAA-3'

iv. PTENP1 reverse primer: 5'-TGATGACGTCCGATTTTTCA-3'

v. ACTIN forward primer: 5'-CATGTACGTTGCTATCCAGGC-3'

vi. ACTIN reverse primer: 5'-CTCCTTAATGTCACGCACGAT-3'

vii. 36B4 forward primer: 5'-GTGTTCGACAATGGCAGCAT-3'

viii. 36B4 reverse primer: 5'-GACACCCTCCAGGAAGCGA-3'

i. 36B4 primer sequences reported in Fullwood et al. (2009).

c. Do not pre-treat with uracil-N-glycosylase.

d. All reactions should be optimized and run in technical triplicate.

8. Using ACTIN as an internal standard, calculate the relative PTEN and PTENP1 expression for each sample using the comparative $\mathrm{Ct}$ method.

a. Additionally perform normalization using 36B4 as an internal standard (additional control).

9. Repeat independently four additional times.

\section{Deliverables}

- Data to be collected:

O Images of fluorescence and phase/contrast of siGLO transfected cells. 
Purity $\left(A_{260 / 280}\right.$ ratio $)$ and concentration of isolated total RNA from cells.

O Raw data for all GPCR reactions.

O Quantification of PTEN and PTENP1 mRNA levels relative to ACTIN or 36B4.

$O$ Quantification of fold change PTEN and PTENP1 mRNA levels relative to siLuc transfected cells.

$O$ Graph of fold change PTEN mRNA expression relative to siLuc. (Compare to Figure 2G, left).

$O$ Graph of fold change PTENP1 mRNA expression relative to siLuc. (Compare to Figure 2G, right).

Confirmatory analysis plan

This replication attempt will perform the following statistical analysis listed below.

- Statistical Analysis:

Note: at the time of analysis, we will perform the Shapiro-Wilk test and generate a quantilequantile plot to assess the normality of the data. We will also perform Levene's test to assess homoscedasticity. If the data appear skewed we will perform the appropriate transformation in order to proceed with the proposed statistical analysis. If this is not possible we will perform the planned comparisons using the Wilcoxon-Mann Whitney test.

O One-way MANOVA of PTEN and PTENP1 mRNA levels in siLuc, siPTEN, siPTENP1, or siPTEN/ PTENP1 siRNA transfected cells with the following planned comparisons using the Bonferroni correction:

1. PTEN mRNA levels of siLuc transfected cells compared to siPTEN transfected cells.

2. PTEN mRNA levels of siLuc transfected cells compared to siPTENP1 transfected cells.

3. PTEN mRNA levels of siLuc transfected cells compared to siPTEN/PTENP1 transfected cells.

4. PTENP1 mRNA levels of siLuc transfected cells compared to siPTEN transfected cells.

5. PTENP1 mRNA levels of siLuc transfected cells compared to siPTENP1 transfected cells.

6. PTENP1 mRNA levels of siLuc transfected cells compared to siPTEN/PTENP1 transfected cells.

- Meta-analysis of effect sizes:

O Compute the effect sizes of each comparison, compare them against the effect size in the original paper and use a random effects meta-analytic approach to combine the original and replication effects, which will be presented as a forest plot.

- Additional exploratory analysis:

The same analysis described above will be performed with $36 B 4$ normalized values, which serves as an independent normalization control not included in the original analysis.

Known differences from the original study

The PTEN and PTENP1 mRNA levels will be normalized with an independent control (36B4) in addition to ACTIN. All known differences are listed in the materials and reagents section above with the originally used item listed in the comments section. All differences have the same capabilities as the original and are not expected to alter the experimental design.

Provisions for quality control

The cell line used in this experiment will undergo STR profiling to confirm their identity and will be sent for mycoplasma testing to ensure there is no contamination. Transfection efficiency will be recorded for each replicate and any transfection that does not contain $>90 \%$ efficiency will be excluded and not continue through the rest of the procedure. If the efficiency in the first attempt(s) does not obtain $>90 \%$, then any modifications to the transfection protocol will be recorded and the procedure will be maintained for the remaining replicates. The sample purity $\left(\mathrm{A}_{260 / 280}\right.$ ratio) of the isolated RNA from each sample will be reported. The PTEN and PTENP1 mRNA levels will be normalized with an independent control (36B4). All the raw data, including the analysis files, will be uploaded to the project page on the OSF (https://osf.io/yyqas) and made publically available.

\section{Protocol 4: Western blot of cells transfected with siRNA}

This experiment utilizes western blot to assess the protein levels of PTEN after depletion of PTEN, PTENP1, or both. It is a replication of Figure $2 \mathrm{H}$.

\section{Sampling}

- Experiment to be repeated a total of five times for a minimum power of $80 \%$. The original data are qualitative, thus to determine an appropriate number of replicates to initially perform, sample sizes based on a range of potential variance was determined. 
O See 'Power calculations' section for details.

- Experiment has 6 conditons:

O Cohort 1: siGENOME non-targeting siRNA \#2 (siLUC) transfected DU145 cells.

O Cohort 2: siPTEN Smartpool (targets PTEN and PTENP1) transfected DU145 cells.

O Cohort 3: siPTEN transfected DU145 cells.

O Cohort 4: siPTENP1 transfected DU145 cells.

O Cohort 5: Uninfected DU145 cells (additional negative control).

O Transfection control: siGLO RISC-free siRNA transfected DU145 cells.

- Western blots performed for:

O PTEN.

O Hsp90 (loading control).

Materials and reagents

\begin{tabular}{|c|c|c|c|c|}
\hline Reagent & Type & Manufacturer & Catalog \# & Comments \\
\hline DU145 cells & Cell line & ATCC & HTB-81 & - \\
\hline RPMI 1640 medium & Cell culture & Sigma-Aldrich & R8758 & $\begin{array}{l}\text { Replaces Invitrogen brand used in original } \\
\text { study }\end{array}$ \\
\hline Fetal bovine serum (FBS) & Cell culture & Sigma-Aldrich & F2442 & $\begin{array}{l}\text { Replaces Invitrogen brand used in original } \\
\text { study }\end{array}$ \\
\hline L-glutamine & Cell culture & Sigma-Aldrich & G7513 & Original brand not specified \\
\hline 100x Penicillin/streptomycin & Cell culture & Sigma-Aldrich & P4333 & Original brand not specified \\
\hline 0.05\% trypsin/0.48 mM EDTA & Cell culture & Sigma-Aldrich & T3924 & Original brand not specified \\
\hline $\begin{array}{l}\text { Phosphate buffered saline (PBS), without } \\
\mathrm{MgCl}_{2} \text { and } \mathrm{CaCl}_{2}\end{array}$ & Cell culture & Sigma-Aldrich & D8537 & Original brand not specified \\
\hline 6 well tissue culture dishes & Labware & Corning & 3516 & Original brand not specified \\
\hline siGLO RISC-free siRNA & Nucleic acid & Dharmacon & D-001600-01 & - \\
\hline $\begin{array}{l}\text { siGENOME non-targeting siRNA \#2 } \\
\text { (siLUC) }\end{array}$ & Nucleic acid & Dharmacon & D-001210-02 & - \\
\hline ON-TARGETplus siPTEN Smartpool & Nucleic acid & Dharmacon & L-003023-00 & $\begin{array}{l}\text { Composed of: J-003023-09; J-003023-10; } \\
\text { J-003023-11; J-003023-12 }\end{array}$ \\
\hline SiPTEN & Nucleic acid & Dharmacon & Custom & $\begin{array}{l}\text { See Supplemental Figure } 6 \text { of original paper } \\
\text { for sequence }\end{array}$ \\
\hline siPTENP1 & Nucleic acid & Dharmacon & Custom & $\begin{array}{l}\text { See Supplemental Figure } 6 \text { of original paper } \\
\text { for sequence }\end{array}$ \\
\hline Dharmafect 1 & Cell culture & Dharmacon & T-2001-01 & - \\
\hline Microscope & Instrument & Olympus & LX81 & Original brand not specified \\
\hline $\begin{array}{l}\text { Rabbit anti-PTEN (clone 138G6) } \\
\text { monoclonal antibody }\end{array}$ & Antibodies & Cell Signaling & 9559 & - \\
\hline Mouse anti-Hsp90 (clone 68) antibody & Antibodies & Becton Dickinson & 610419 & Original catalog number not specified \\
\hline Secondary antibody (anti-rabbit lgG) & Antibodies & Cell Signaling & 7074 & Original brand not specified \\
\hline Secondary antibody (anti-mouse lgG) & Antibodies & Cell Signaling & 7076 & Original brand not specified \\
\hline $\begin{array}{l}\text { ECL DualVue Western Markers } \\
(15-150 \mathrm{kDa})\end{array}$ & Western blot reagent & Sigma-Aldrich & GERPN810 & Original brand not specified \\
\hline Tris & Chemical & \multirow{8}{*}{\multicolumn{3}{|c|}{$\begin{array}{l}\text { Specific brand information will be left up to the discretion of the replicating lab and } \\
\text { recorded later }\end{array}$}} \\
\hline EDTA & Chemical & & & \\
\hline $\mathrm{MgCl}_{2}$ & Chemical & & & \\
\hline $\mathrm{NaCl}$ & Chemical & & & \\
\hline $\mathrm{NP}_{4} \mathrm{O}$ & Chemical & & & \\
\hline$\beta$-glycerophsphate & Chemical & & & \\
\hline $\mathrm{NaVO}_{4}$ & Chemical & & & \\
\hline $\mathrm{NaF}$ & Chemical & & & \\
\hline
\end{tabular}

Continued on next page 
Continued

\begin{tabular}{|c|c|c|c|c|}
\hline Reagent & Type & Manufacturer & Catalog \# & Comments \\
\hline Protease inhibitor cocktail (mammalian) & Inhibitor & Sigma-Aldrich & P8340 & Original brand not specified \\
\hline Sonifier & Instrument & Branson Digital & $\mathrm{n} / \mathrm{a}$ & Original brand not specified \\
\hline Bradford Reagent & Reporter assay & Sigma-Aldrich & B6916 & Original brand not specified \\
\hline TruPAGE LDS sample buffer (4x) & Buffer & Sigma-Aldrich & PCG3009 & Original brand not specified \\
\hline TruPAGE DTT sample reducer $(10 x)$ & Buffer & Sigma-Aldrich & PCG3005 & - \\
\hline XCell SureLOCK Mini-cell system & Instrument & Life Technologies & $\mathrm{n} / \mathrm{a}$ & Original brand not specified \\
\hline 4-12\% TruPAGE SDS-PAGE gel & Western blot reagent & Sigma-Aldrich & PCG2003 & Replaces NuPage gels \\
\hline $\begin{array}{l}\text { TruPAGE TEA-Tricine SDS running } \\
\text { buffer }(20 \times)\end{array}$ & Buffer & Sigma-Aldrich & PCG3001 & Original brand not specified \\
\hline Xcell II Blot Module & Instrument & Life Technologies & $\mathrm{n} / \mathrm{a}$ & Original brand not specified \\
\hline Hybond ECL nitrocellulose membrane & Western blot reagent & Sigma-Aldrich & GERPN2020D & Original brand not specified \\
\hline TruPAGE transfer buffer (20x) & Buffer & Sigma-Aldrich & PCG3011 & Original brand not specified \\
\hline Ponceau S solution & Buffer & Sigma-Aldrich & P7170 & - \\
\hline 10x Tris buffered saline (TBS) & Buffer & Sigma-Aldrich & T5912 & Original brand not specified \\
\hline ECL Prime Western blotting system & Detection assay & Sigma-Aldrich & GERPN2232 & Original brand not specified \\
\hline Image J & Software & $\mathrm{NIH}$ & Version 10.2 & - \\
\hline
\end{tabular}

\section{Procedure}

\section{Note}

- All cells will be sent for mycoplasma testing and STR profiling.

- DU145 cells grown in complete RPMI 1640: RPMI 1640 supplemented with 2 mM glutamine, 10\% FBS, $100 \mathrm{U} / \mathrm{ml}$ penicillin and $100 \mu \mathrm{g} / \mathrm{ml}$ streptomycin at $37^{\circ} \mathrm{C}$ and $6 \% \mathrm{CO}_{2}$.

1. Seed $3.75 \times 10^{5}$ DU145 cells per well in a 6-well dish. Grow overnight.

2. Transfect with $100 \mathrm{nM}$ siRNAs (siPTEN, siPTENP1, siPTEN Smartpool (siPTEN/PTENP1), or siLuc in separate wells) using Dharmafect 1 according to manufacturer's instructions or leave untransfected. Transfect control cells with siGLO RISC-free control siRNA according to manufacturer's instructions. Grow overnight.

3. Confirm that $>90 \%$ of siGLO transfected control cells show fluorescence, indicating they were successfully transfected.

a. If transfection is less than $90 \%$, record efficiency for attempt, exclude attempt and do not continue with the rest of the procedure. Repeat procedure until $>90 \%$ efficiency is obtained.

b. If modification to transfection (step 2) is needed, record and maintain modified steps for remaining replicates.

4. $48 \mathrm{hr}$ after transfection lyse cells transfected with siRNAs and uninfected cells in lysis buffer on ice for $30 \mathrm{~min}$.

a. Lysis buffer: $50 \mathrm{mM}$ Tris pH8.0, $1 \mathrm{mM}$ EDTA, $1 \mathrm{mM} \mathrm{MgCl} 2,150 \mathrm{mM} \mathrm{NaCl}, 1 \% \mathrm{NP}-40,1 \mathrm{mM}$ $\beta$-glycerophosphate, $1 \mathrm{mM} \mathrm{Na} \mathrm{VO}_{4}, 1 \mathrm{mM} \mathrm{NaF}$, protease inhibitors.

5. Gently sonicate protein lysate for 3 to 4 bursts for 5 to $10 \mathrm{~s}$. Clear lysate by centrifugation at $10,000 \times g$ for $10 \mathrm{~min}$ at $4^{\circ} \mathrm{C}$.

6. Perform Bradford protein determination assay following manufacturer's instructions.

7. Separate $30 \mu \mathrm{g}$ of protein (in $1 \times$ sample buffer and sample reducer) per lane on a $4-12 \%$ Tris Glycine SDS-PAGE gel with protein ladder following manufacturer's instructions.

a. Sample run per gel:

i. Protein molecular weight marker.

ii. Untransfected DU145 cells.

iii. DU145 cells transfected with siGENOME non-targeting siRNA \#2.

iv. DU145 cells transfected with siPTEN.

v. DU145 cells transfected with siPTENP1.

vi. DU145 cells transfected with siPTEN/PTENP1. 
8. Transfer to nitrocellulose membrane (pre-wetted with methanol before use) at $25 \mathrm{~V}$ constant for 1-2 hr in $1 \times$ transfer buffer with $20 \%$ methanol following manufacturer's instructions.

a. After transfer, stain membrane with Ponceau S solution following manufacturer's instructions to visualize transferred protein. Image membrane, then wash out the Ponceau stain (additional quality control step).

9. Perform western blotting with the following antibodies following manufacturer's instructions. Use $1 \times$ TBS for washes and blocking reagent recommended by manufacturer.

a. rabbit anti-PTEN; use at 1:1000 dilution; $54 \mathrm{kDa}$.

b. mouse anti-Hsp90; use at 1:1000 dilution; $90 \mathrm{kDa}$.

10. Detect signal with appropriate HRP conjugated secondary antibody followed by chemiluminescence following manufacturer's instructions.

11. Analyze scanned images using Image J software.

a. Equal-sized regions of interest (ROI) will be positioned on specific bands.

b. Background will be located within each individual lane but not occupied by any other discrete band.

c. Subtract background pixel intensity from ROI pixel intensity.

d. Normalize PTEN values by Hsp90 values from the same sample.

12. Repeat independently four additional times.

\section{Deliverables}

- Data to be collected:

Images of fluorescence and phase/contrast of siGLO transfected cells.

Images of Ponceau stained membranes and full films for all western blots with ladder. (Compare to Figure $2 \mathrm{H}$ ).

Raw data file of ROI and background pixel intensities.

O Normalize PTEN values for each sample.

Confirmatory analysis plan

This replication attempt will perform the following statistical analysis listed below.

- Statistical Analysis:

Note: at the time of analysis, we will perform the Shapiro-Wilk test and generate a quantilequantile plot to assess the normality of the data. We will also perform Levene's test to assess homoscedasticity. If the data appear skewed we will perform the appropriate transformation in order to proceed with the proposed statistical analysis. If this is not possible we will perform the equivalent non-parametric test.

O Two-way ANOVA of normalized PTEN levels in siLuc, siPTEN, siPTENP1, or siPTEN/PTENP1 siRNA transfected cells with the following planned comparisons using the Bonferroni correction:

1. siLuc compared to siPTEN.

2. siLuc compared to siPTENP1.

3. siLuc compared to siPTEN/PTENP1.

4. siPTEN/PTENP1 compared to siPTEN.

5. siPTEN/PTENP1 compared to siPTENP1.

- Meta-analysis of effect sizes:

The replication data (mean and $95 \%$ confidence interval) will be plotted with the original reported data value plotted as a single point on the same plot for comparison.

Known differences from the original study

The original study used 12 well plates seeded with $1.5 \times 10^{5}$ DU145 cells per well, which was increased $2.5 \times$ to account for the difference in cell surface area. All known differences are listed in the materials and reagents section above with the originally used item listed in the comments section. All differences have the same capabilities as the original and are not expected to alter the experimental design.

\section{Provisions for quality control}

The cell line used in this experiment will undergo STR profiling to confirm their identity and will be sent for mycoplasma testing to ensure there is no contamination. Transfection efficiency will be recorded for each replicate and any transfection that does not contain $>90 \%$ efficiency will be excluded and not continue through the rest of the procedure. If the efficiency in the first attempt 
(s) does not obtain $>90 \%$, then any modifications to the transfection protocol will be recorded and the procedure will be maintained for the remaining replicates. Ponceau stained membranes will be used to assess completeness of transfer. All the raw data, including the analysis files, will be uploaded to the project page on the OSF (https://osf.io/yyqas) and made publically available.

\section{Protocol 5: Quantitative PCR following PTEN 3' UTR transfection}

This experiment tests the effect of expressing the 3' UTR of PTENP1 on mRNA expression levels of PTENP1. It is a replication of the left panel of Figure 4A.

\section{Sampling}

- Experiment to be repeated a total of three times for a minimum power of $98 \%$.

O See 'Power calculations' section for details.

- Experiment has 3 conditions:

O Cohort 1: pCMV transfected DU145 cells.

O Cohort 2: pCMV/PTEN 3' UTR transfected DU145 cells.

O Cohort 3: Uninfected DU145 cells (additional negative control).

- Quantitative RT-PCR performed in technical triplicate for the following genes:

O PTENP1.

O ACTIN (internal control).

O 36B4 (additional internal control).

Materials and reagents

\begin{tabular}{|c|c|c|c|c|}
\hline Reagent & Type & Manufacturer & Catalog \# & Comments \\
\hline DU145 cells & Cell line & ATCC & HTB-81 & - \\
\hline RPMI 1640 medium & Cell culture & Sigma-Aldrich & R8758 & $\begin{array}{l}\text { Replaces Invitrogen brand used in original } \\
\text { study }\end{array}$ \\
\hline Fetal bovine serum (FBS) & Cell culture & Sigma-Aldrich & F2442 & $\begin{array}{l}\text { Replaces Invitrogen brand used in original } \\
\text { study }\end{array}$ \\
\hline L-glutamine & Cell culture & Sigma-Aldrich & G7513 & Original brand not specified \\
\hline 100x Penicillin/streptomycin & Cell culture & Sigma-Aldrich & P4333 & Original brand not specified \\
\hline 0.05\% trypsin/0.48 mM EDTA & Cell culture & Sigma-Aldrich & T3924 & Original brand not specified \\
\hline $\begin{array}{l}\text { Phosphate buffered saline (PBS), without } \\
\mathrm{MgCl}_{2} \text { and } \mathrm{CaCl}_{2}\end{array}$ & Cell culture & Sigma-Aldrich & D8537 & Original brand not specified \\
\hline $60 \mathrm{~mm}$ tissue culture dishes & Labware & Corning & 430166 & Original brand not specified \\
\hline Endo-free maxiprep kit & Kit & Sigma-Aldrich & NA0400 & - \\
\hline pCMV (empty vector) & DNA construct & Original lab & $\mathrm{n} / \mathrm{a}$ & From original lab \\
\hline pCMV/PTEN 3' UTR & DNA construct & Original lab & $\mathrm{n} / \mathrm{a}$ & From original lab \\
\hline Effectene & Cell culture & Qiagen & 301425 & Original brand not specified \\
\hline PTENP1 forward and reverse primers & Nucleic acid & \multirow{3}{*}{\multicolumn{3}{|c|}{$\begin{array}{l}\text { Specific brand information will be left up to the discretion of the replicating lab and recorded } \\
\text { later }\end{array}$}} \\
\hline ACTIN forward and reverse primers & Nucleic acid & & & \\
\hline 36B4 forward and reverse primers & Nucleic acid & & & \\
\hline TRI reagent & Chemical & Sigma-Aldrich & T9424 & Replaces Trizol reagent from Invitrogen \\
\hline 1-bromo-3-chloropropase & Chemical & Sigma-Aldrich & B9673 & Reagent needed from TRI reagent protocol \\
\hline Nuclease free water & Chemical & Sigma-Aldrich & W4502 & Reagent needed from TRI reagent protocol \\
\hline DNAse I amplification grade & Chemical & Sigma-Aldrich & AMPD1 & $\begin{array}{l}\text { Replaces Invitrogen brand used in original } \\
\text { study }\end{array}$ \\
\hline $\begin{array}{l}\text { First-strand cDNA synthesis kit (includes } \\
\text { pd(N)6 random hexamers and Notl-(dT) } \\
18 \text { primers) }\end{array}$ & Kit & Sigma-Aldrich & GE27-9261-01 & $\begin{array}{l}\text { Replaces SuperScript II reverse transcriptase } \\
\text { from Invitrogen used in original study }\end{array}$ \\
\hline QuantiTect Sybr Green PCR kit & Kit & Qiagen & 204141 & - \\
\hline Real-time PCR system & Instrument & Applied Biosystems & 7500 Fast & $\begin{array}{l}\text { Replaces Roche Lightcycler } 2.0 \text { used in } \\
\text { original study }\end{array}$ \\
\hline
\end{tabular}




\section{Procedure}

\section{Note}

- All cells will be sent for mycoplasma testing and STR profiling.

- DU145 cells grown in complete RPMI 1640: RPMI 1640 supplemented with 2 mM glutamine, 10\% FBS, $100 \mathrm{U} / \mathrm{ml}$ penicillin and $100 \mu \mathrm{g} / \mathrm{ml}$ streptomycin at $37^{\circ} \mathrm{C}$ and $6 \% \mathrm{CO}_{2}$.

1. Grow and prepare endotoxin-free plasmid constructs following manufacturer's instructions for an endotoxin-free plasmid maxiprep kit.

a. pCMV (empty vector).

b. PCMVIPTEN 3' UTR.

i. Sequence gene of interest in each plasmid and run whole plasmids on agarose gel to confirm vector integrity.

2. Seed $3.5 \times 10^{5}$ DU145 cells per dish in $6 \mathrm{~cm}$ dishes. Grow overnight.

3. Transfect with $\mathrm{PCMV}$ or PCMV/PTEN 3' UTR plasmids using Effectene according to manufacturer's instructions and recommended DNA and reagent amounts.

4. $24 \mathrm{hr}$ after transfection, extract total RNA from each cohort directly on the culture dish using TRI reagent and 1-bromo-3-chloropropane according to manufacturer's instructions.

5. Treat RNA with DNase I following manufacturer's instructions.

6. Reverse transcribe $1 \mu \mathrm{g}$ RNA/sample into cDNA using first-strand cDNA synthesis kit with primers following manufacturer's instructions.

a. Record RNA concentration and purity $\left(A_{280} / A_{260}\right)$.

7. Perform quantitative PCR reaction using the QuantiTect SYBR Green PCR kit:
a. Use $2 \mu \mathrm{l}$ of reverse transcription reaction per $20 \mu \mathrm{l}$ real-time PCR reaction.

b. Perform quantitative PCR for PTENP1, ACTIN, and 36B4.

i. PTENP1 forward primer: 5'-TCAGAACATGGCATACACCAA-3'

ii. PTENP1 reverse primer: 5'-TGATGACGTCCGATTTTTCA-3'

iii. ACTIN forward primer: 5'-CATGTACGTTGCTATCCAGGC-3'

iv. ACTIN reverse primer: 5'-CTCCTTAATGTCACGCACGAT-3'

v. 36B4 forward primer: 5'-GTGTTCGACAATGGCAGCAT-3'

vi. $36 B 4$ reverse primer: 5'-GACACCCTCCAGGAAGCGA-3'

c. $36 B 4$ primer sequences reported in Fullwood et al. (2009).

d. Do not pre-treat with uracil-N-glycosylase.

e. All reactions should be optimized and run in technical triplicate.

8. Using ACTIN as an internal standard, calculate the fold change in PTEN1P expression relative to pCMV expressing cells using the comparative $\mathrm{Ct}$ method.

a. Additionally perform normalization using 36B4 as an internal standard (additional control).

9. Repeat independently two additional times.

\section{Deliverables}

- Data to be collected:

Purity $\left(\mathrm{A}_{260 / 280}\right.$ ratio) and concentration of isolated total RNA from cells.

$O$ Raw data for all qPCR reactions.

O Quantification of PTENP1 mRNA levels relative to ACTIN or $36 B 4$.

O Quantification of fold change PTENP1 mRNA levels relative to pCMV transfected cells. (Compare to Figure 4A, left panel).

Confirmatory analysis plan

This replication attempt will perform the following statistical analysis listed below.

- Statistical Analysis:

O Note: at the time of analysis, we will perform the Shapiro-Wilk test and generate a quantile-quantile plot to assess the normality of the data. We will also perform Levene's test to assess homoscedasticity. If the data appear skewed we will perform the appropriate transformation in order to proceed with the proposed statistical analysis. If this is not possible we will perform the equivalent non-parametric test.

O Unpaired two-tailed $t$-test of PTENP1 mRNA levels of pCMV transfected cells compared to pCMV/PTEN 3' UTR transfected cells. 
- Meta-analysis of effect sizes:

O Compute the effect sizes of each comparison, compare them against the effect size in the original paper and use a random effects meta-analytic approach to combine the original and replication effects, which will be presented as a forest plot.

- Additional exploratory analysis:

The same analysis described above will be performed with $36 B 4$ normalized values, which serves as an independent normalization control not included in the original analysis.

Known differences from the original study

The PTENP1 mRNA levels will be normalized with an independent control (36B4) in addition to ACTIN. All known differences are listed in the materials and reagents section above with the originally used item listed in the comments section. All differences have the same capabilities as the original and are not expected to alter the experimental design.

\section{Provisions for quality control}

The cell line used in this experiment will undergo STR profiling to confirm their identity and will be sent for mycoplasma testing to ensure there is no contamination. The sample purity $\left(A_{260 / 280}\right.$ ratio $)$ of the isolated RNA from each sample will be reported. The PTENP1 mRNA levels will be normalized with an independent control (36B4). All the raw data, including the analysis files, will be uploaded to the project page on the OSF (https://osf.io/yyqas) and made publically available.

\section{Protocol 6: Cell growth assay following PTEN 3' UTR transfection}

This experiment tests the effect of expressing the $3^{\prime}$ UTR of PTENP1 on cell growth. It is a replication of the right panel of Figure 4A.

Sampling

- Experiment to be repeated a total of three times for a minimum power of $98 \%$. O See 'Power calculations' section for details.

- Experiment has 3 conditions:

Cohort 1: pCMV transfected DU145 cells.

O Cohort 2: pCMV/PTEN 3' UTR transfected DU145 cells.

O Cohort 3: Uninfected DU145 cells (additional negative control).

- Each cohort is harvested on the following days performed in technical triplicate:

$\mathrm{O}$ Day 0 (after $\mathrm{O} / \mathrm{N}$ incubation).

O Day 1.

O Day 2.

Day 3.

Day 4.

Day 5.

Materials and reagents

\begin{tabular}{lllll}
\hline Reagent & Type & Manufacturer & Catalog \# & Comments \\
\hline DU145 cells & Cell line & ATCC & HTB-81 & - \\
\hline RPMI 1640 medium & Cell culture & Sigma-Aldrich & R8758 & Replaces Invitrogen brand used in original study \\
\hline Fetal bovine serum (FBS) & Cell culture & Sigma-Aldrich & F2442 & Replaces Invitrogen brand used in original study \\
\hline L-glutamine & Cell culture & Sigma-Aldrich & G7513 & Original brand not specified \\
\hline $100 \times$ Penicillin/streptomycin & Cell culture & Sigma-Aldrich & P4333 & Original brand not specified \\
\hline $0.05 \%$ trypsin/0.48 mM EDTA & Cell culture & Sigma-Aldrich & T3924 & Original brand not specified \\
\hline $\begin{array}{l}\text { Phosphate buffered saline (PBS), without } \\
\text { MgCl }_{2} \text { and CaCl }\end{array}$ & Cell culture & Sigma-Aldrich & D8537 & Original brand not specified \\
\hline 60 mm tissue culture dishes & Labware & Corning & 430166 & Original brand not specified \\
\hline $\mathrm{pCMV} \mathrm{(empty} \mathrm{vector)}$ & DNA construct & Original lab & $\mathrm{n} / \mathrm{a}$ & From original lab
\end{tabular}

Continued on next page 
Continued

\begin{tabular}{|c|c|c|c|c|}
\hline Reagent & Type & Manufacturer & Catalog \# & Comments \\
\hline PCMV/PTEN 3' UTR & DNA construct & Original lab & $\mathrm{n} / \mathrm{a}$ & From original lab \\
\hline Effectene & Cell culture & Qiagen & 301425 & Original brand not specified \\
\hline 12 well tissue culture dishes & Labware & Corning & 3513 & Original brand not specified \\
\hline Crystal violet & Dye & Sigma-Aldrich & $\mathrm{C} 0775$ & Original brand not specified \\
\hline Formalin & Chemical & \multirow{3}{*}{\multicolumn{3}{|c|}{$\begin{array}{l}\text { Specific brand information will be left up to the discretion of the replicating lab and recorded } \\
\text { later }\end{array}$}} \\
\hline Acetic acid & Chemical & & & \\
\hline Methanol & Chemical & & & \\
\hline $\begin{array}{l}\text { Spectrophotometer capable of reading } \\
\text { at } 590 \mathrm{~nm} \text { (or } 595 \mathrm{~nm} \text { ) }\end{array}$ & Instrument & Alamolabs & & Original brand not specified \\
\hline
\end{tabular}

\section{Procedure}

\section{Note}

- All cells will be sent for mycoplasma testing and STR profiling.

- DU145 cells grown in complete RPMI 1640: RPMI 1640 supplemented with 2 mM glutamine, 10\% FBS, $100 \mathrm{U} / \mathrm{ml}$ penicillin and $100 \mu \mathrm{g} / \mathrm{ml}$ streptomycin at $37^{\circ} \mathrm{C}$ and $6 \% \mathrm{CO}_{2}$.

1. Seed $3.5 \times 10^{5}$ DU145 cells per dish in $6 \mathrm{~cm}$ dishes. Grow overnight.

2. Transfect with $\mathrm{pCMV}$ or $\mathrm{pCMV/PTEN} \mathrm{3'} \mathrm{UTR} \mathrm{plasmids} \mathrm{using} \mathrm{Effectene} \mathrm{according} \mathrm{to} \mathrm{manufacturer's}$ instructions and recommended DNA and reagent amounts.

a. Plasmids prepped in Protocol 7.

3. $6 \mathrm{hr}$ after transfection, resuspend $2 \times 10^{5} \mathrm{pCMV}, \mathrm{pCMV} / \mathrm{PTEN} 3^{\prime}$ UTR, and untransfected cells in 50 $\mathrm{ml}$ fresh media. Seed three wells of six sets of 12-well plates with $2 \mathrm{ml}$ of each cell line. Each set of 12 well plates should have three wells containing untransfected cells, three wells containing pCMVtransfected cells, and three wells containing pCMV/PTEN 3' UTR-transfected cells. Incubate overnight.

4. Fix one plate every $24 \mathrm{hr}$ starting after overnight incubation (the first plate fixed will be called day 0$)$.

a. Wash wells once in PBS.

b. Fix wells with $10 \%$ formalin for $10 \mathrm{~min}$ at room temperature.

c. Store plates in PBS at $4^{\circ} \mathrm{C}$.

d. All wells should be fixed by day 6 .

5. Stain cells with $0.1 \%$ crystal violet, $20 \%$ methanol for $15 \mathrm{~min}$. Wash cells.

6. Lyse all wells with $10 \%$ acetic acid for $10 \mathrm{~min}$.

7. Read optical density at $590 \mathrm{~nm}$.

a. Reading can be done at $595 \mathrm{~nm}$ if $590 \mathrm{~nm}$ is not available.

8. Repeat independently two additional times.

\section{Deliverables}

- Data to be collected:

Raw data of absorbance from plate reader.

Relative absorbance for each cohort over time. (Compare to Figure 4A, right panel).

Confirmatory analysis plan

This replication attempt will perform the following statistical analysis listed below.

- Statistical Analysis:

Note: at the time of analysis, we will perform the Shapiro-Wilk test and generate a quantilequantile plot to assess the normality of the data. We will also perform Levene's test to assess homoscedasticity. If the data appear skewed we will perform the appropriate transformation in order to proceed with the proposed statistical analysis. If this is not possible we will perform the equivalent non-parametric test.

Unpaired two-tailed $t$-test of Day 5 absorbance of pCMV transfected cells compared to pCMV/ PTEN 3' UTR transfected cells. 
Unpaired two-tailed t-test of AUC measurements (determined from day 0, 1, 2, 3, 4, and 5 for each replicate) of pCMV transfected cells compared to PCMV/PTEN 3' UTR transfected cells.

- Meta-analysis of effect sizes:

Compute the effect sizes of each comparison, compare them against the effect size in the original paper and use a random effects meta-analytic approach to combine the original and replication effects, which will be presented as a forest plot.

Known differences from the original study

All known differences are listed in the materials and reagents section above with the originally used item listed in the comments section. All differences have the same capabilities as the original and are not expected to alter the experimental design.

Provisions for quality control

The cell line used in this experiment will undergo STR profiling to confirm their identity and will be sent for mycoplasma testing to ensure there is no contamination. All the raw data, including the analysis files, will be uploaded to the project page on the OSF (https://osf.io/yyqas) and made publically available.

\section{Power calculations}

For additional details on power calculations, please see analysis scripts and associated files on the OSF:

https://osf.io/cd2yq/

\section{Protocol 1}

Summary of original data estimated from graph reported in Figure 1D:

\begin{tabular}{lllll} 
siRNA & mRNA & Mean & Stdev & N \\
\hline \multirow{2}{*}{ siLUC } & PTEN & 1.00 & 0.239 & 3 \\
\cline { 2 - 5 } & PTENP1 & 1.00 & 0.386 & 3 \\
\hline \multirow{2}{*}{$19 \mathrm{~b}$} & PTEN & 0.286 & 0.085 & 3 \\
\cline { 2 - 5 } & PTENP1 & 0.234 & 0.065 & 3 \\
\hline $20 \mathrm{a}$ & PTEN & 0.458 & 0.167 & 3 \\
\cline { 2 - 5 } & PTENP1 & 0.250 & 0.080 & 3 \\
\hline
\end{tabular}

Test family

- 2 tailed $t$ test, Wilcoxon-Mann-Whitney test, Bonferroni's correction: alpha error $=0.0125$.

'Power calculations' performed with G*Power software, version 3.1.7 (Faul et al., 2007).

\begin{tabular}{llllll} 
Group 1 & Group 2 & Effect size d & A priori power & Group 1 sample size & Group 2 sample size \\
\hline siLuc PTEN mRNA & 19b PTEN mRNA & 3.98555 & $91.9 \% *$ & $4^{\star}$ & $4^{\star}$ \\
\hline siLuc PTEN mRNA & 20a PTEN mRNA & 2.62999 & $88.3 \%$ & 6 & 6 \\
\hline siLuc PTENP1 mRNA & 19b PTENP1 mRNA & 2.76532 & $80.7 \% \dagger$ & $5 \dagger$ & $5 \dagger$ \\
\hline siLuc PTENP1 mRNA & 20a PTENP1 mRNA & 2.68908 & $89.8 \%$ & 6 & 6
\end{tabular}

*6 samples per group will be used based on the siLuc to 20a PTEN comparison making the power $99.9 \%$.

†6 samples per group will be used based on the siLuc to 20a PTEN comparison making the power $91.6 \%$.

\section{Test family}

- Due to the large variance, these parametric tests are only used for comparison purposes. The sample size is based on the non-parametric tests listed above.

- Two-way ANOVA: Fixed effects, special, main effects and interactions: alpha error =0.05. 
Due to a lack of raw original data, we are unable to perform power calculations using a MANOVA. We are using a two-way ANOVA to estimate sample size.

'Power calculations' performed with G*Power software, version 3.1.7 (Faul et al., 2007).

ANOVA $F$ test statistic and partial $\eta^{2}$ performed with $R$ software, version 3.1.2 ( $R$ Development Core Team, 2014).

Groups

siLUC, 19b, 20a (PTEN and PTENP1 mRNA for all)

\section{F test statistic}

$F(2,12)=23.1978$ (main effect: siRNA) 0.79451
Partial $\eta^{2}$ Effect size $f$ A priori power

Total sample size

*36 total samples (6 per group) will be used based on the planned comparisons making the power $99.9 \%$.

\section{Test family}

- Due to the large variance, these parametric tests are only used for comparison purposes. The sample size is based on the non-parametric tests listed above.

- 2 tailed $t$ test, difference between two independent means, Bonferroni's correction: alpha error = 0.0125 .

'Power calculations' performed with G*Power software, version 3.1.7 (Faul et al., 2007).

\begin{tabular}{llllll} 
Group 1 & Group 2 & Effect size $d$ & A priori power & Group 1 sample size & Group 2 sample size \\
\hline siLuc PTEN mRNA & 19b PTEN mRNA & 3.98555 & $94.2 \%{ }^{*}$ & $4^{\star}$ & $4^{\star}$ \\
\hline siLuc PTEN mRNA & 20a PTEN mRNA & 2.62999 & $90.6 \%$ & 6 & 6 \\
\hline siLuc PTENP1 mRNA & 19b PTENP1 mRNA & 2.76532 & $84.0 \% \dagger$ & $5 \dagger$ & $5 \dagger$ \\
\hline siLuc PTENP1 mRNA & 20a PTENP1 mRNA & 2.68908 & $81.6 \% \ddagger$ & $5 \ddagger$ & $5 \ddagger$
\end{tabular}

*6 samples per group will be used based on the siLuc to 20a PTEN comparison making the power $99.9 \%$.

†6 samples per group will be used based on the siLuc to 20a PTEN comparison making the power $93.4 \%$.

$\$ 6$ samples per group will be used based on the siLuc to 20a PTEN comparison making the power $91.9 \%$.

\section{Protocol 2}

Summary of original data estimated from graph reported in Figure 2F:

\begin{tabular}{lllll} 
SiRNA & Day & Mean & Stdev & N \\
\hline siluc & 0 & 1.000 & 0 & 3 \\
\cline { 2 - 5 } & 1 & 0.955 & 0.108 & 3 \\
\hline & 2 & 0.928 & 0.108 & 3 \\
\hline & 3 & 1.252 & 0.108 & 3 \\
\hline \multirow{2}{*}{ siPTEN } & 4 & 1.315 & 0.108 & 3 \\
\cline { 2 - 5 } & 5 & 1.604 & 0.108 & 3 \\
\cline { 2 - 5 } & 0 & 1.000 & 0 & 3 \\
\hline & 1 & 1.198 & 0.108 & 3 \\
\hline & 2 & 1.306 & 0.108 & 3 \\
\hline & 3 & 2.045 & 0.108 & 3 \\
\hline & 4 & 2.414 & 0.108 & 3 \\
\hline
\end{tabular}

Continued on next page 


\begin{tabular}{lllll}
$\begin{array}{l}\text { Continued } \\
\text { siRNA }\end{array}$ & Day & Mean & Stdev & N \\
\hline siPTENP1 & 0 & 1.000 & 0 & 3 \\
\cline { 2 - 5 } & 1 & 1.162 & 0.108 & 3 \\
\cline { 2 - 5 } & 2 & 1.099 & 0.108 & 3 \\
\hline & 3 & 1.613 & 0.108 & 3 \\
\hline siPTEN/PTENP1 & 4 & 1.775 & 0.108 & 3 \\
\cline { 2 - 5 } & 5 & 2.613 & 0.108 & 3 \\
\cline { 2 - 5 } & 0 & 1.000 & 0 & 3 \\
\cline { 2 - 5 } & 1 & 1.198 & 0.108 & 3 \\
\cline { 2 - 5 } & 2 & 1.387 & 0.108 & 3 \\
\hline & 3 & 2.396 & 0.108 & 3 \\
\hline
\end{tabular}

AUC calculations from estimated values.

Calculations performed with R software 3.1.2 (R Development Core Team, 2014).

\begin{tabular}{lllll} 
siRNA & Days & Mean & Stdev & N \\
\hline siLuc & $0,1,2,3,4,5$ & 5.752 & 0.486 & 3 \\
\hline siPTEN & $0,1,2,3,4,5$ & 9.541 & 0.550 & 3 \\
\hline siPTENP1 & $0,1,2,3,4,5$ & 7.455 & 0.486 & 3 \\
\hline siPTEN/PTENP1 & $0,1,2,3,4,5$ & 11.288 & 0.518 & 3
\end{tabular}

\section{Test family}

- Two-way ANOVA: Fixed effects, special, main effects and interactions: alpha error =0.05.

'Power calculations' performed with G*Power software, version 3.1.7 (Faul et al., 2007).

ANOVA $F$ test statistic and partial $\eta^{2}$ performed with $\mathrm{R}$ software, version 3.1.2 ( $R$ Development Core Team, 2014).

\section{Day 5 values}

\section{Groups}

siLUC, siPTEN, siPTENP1, siPTEN/ PTENP1

\section{F test statistic}

$F(1,8)=798.9603$ (main effect: siPTEN) $0.99009 \quad 9.99337$

$F(1,8)=143.7867$ (main effect: siPTENP1) $0.94729 \quad 4.23948$
Partial $\eta^{2}$ Effect size $f$ A priori power Total sample size

92.0\%* $\quad 5^{\star}(4$ groups)

*16 total samples (4 per group) will be used based on the planned comparisons making the power $99.9 \%$.

\section{AUC values}

Groups

SiLUC, siPTEN, siPTENP1, siPTEN/ PTENP1

\section{F test statistic}

$F(1,8)=166.9731$ (main effect: siPTEN) $0.95428 \quad 4.56857$

$F(1,8)=34.2219$ (main effect: siPTENP1) $0.81053 \quad 2.06827$
Partial $\eta 2$ Effect size $f$ A priori power Total sample size

99.8\%* $\quad$ 6* (4 groups)

93.9\%* $\quad 7 *(4$ groups $)$

*16 total samples (4 per group) will be used based on the planned comparisons making the power $99.9 \%$. 


\section{Test family}

- 2 tailed $t$ test, difference between two independent means, Bonferroni's correction: alpha error $=0.01$.

'Power calculations' performed with G*Power software, version 3.1.7 (Faul et al., 2007).

Day 5 values

\begin{tabular}{|c|c|c|c|c|c|}
\hline Group 1 & Group 2 & Effect size $d$ & A priori power & Group 1 sample size & Group 2 sample size \\
\hline siluc & siPTEN & 15.54994 & $91.1 \% *$ & $2^{\star}$ & $2^{\star}$ \\
\hline siluc & siPTENP1 & 6.15404 & $91.1 \% *$ & $3^{*}$ & $3^{*}$ \\
\hline siluc & siPTEN/PTENP1 & 23.24249 & $99.9 \% *$ & $2^{\star}$ & $2^{\star}$ \\
\hline siPTEN/PTENP1 & siPTEN & 7.69255 & $99.4 \% *$ & $3^{*}$ & $3^{\star}$ \\
\hline siPTEN/PTENP1 & siPTENP1 & 17.08845 & $94.6 \% *$ & $2^{*}$ & $2^{\star}$ \\
\hline
\end{tabular}

*5 samples per group will be used based on the AUC calculation planned comparisons making the power $99.9 \%$.

\section{AUC values}

\begin{tabular}{llllll} 
Group 1 & Group 2 & Effect size d & A priori power & Group 1 sample size & Group 2 sample size \\
\hline siLuc & siPTEN & 7.41636 & $99.1 \%^{*}$ & $3^{*}$ & $3^{*}$ \\
\hline siLuc & siPTENP1 & 3.33339 & $93.8 \%$ & 5 & $5^{\star}$ \\
\hline siLuc & siPTEN/PTENP1 & 10.83794 & $99.9 \%^{\star}$ & $3^{*}$ & $4 \dagger$ \\
\hline siPTEN/PTENP1 & siPTEN & 3.42158 & $81.3 \% \dagger$ & $4 \dagger$ & $3^{*}$ \\
\hline siPTEN/PTENP1 & siPTENP1 & 7.50454 & $99.3 \%^{*}$ & $3^{*}$ & \\
\hline
\end{tabular}

*5 samples per group will be used based on the siLuc to siPTENP1 comparison making the power $99.9 \%$.

t5 samples per group will be used based on the siLuc to siPTENP1 comparison making the power 95.0\%.

\section{Protocol 3}

Summary of original data estimated from graph reported in Figure 2G:

\begin{tabular}{lllll} 
& mRNA & Mean & Stdev & N \\
\hline siLUC & PTEN & 1.000 & 0.249 & 3 \\
\cline { 2 - 5 } & PTENP1 & 1.000 & 0.155 & 3 \\
\hline \multirow{2}{*}{ SiPTEN } & PTEN & 0.116 & 0.065 & 3 \\
\hline \multirow{nyyy}{*}{ SiPTENP1 } & PTENP1 & 0.543 & 0.099 & 3 \\
\cline { 2 - 5 } & PTEN & 0.381 & 0.086 & 3 \\
\hline SiPTEN/PTENP1 & PTENP1 & 0.269 & 0.094 & 3 \\
\cline { 2 - 5 } & PTEN & 0.193 & 0.067 & 3 \\
\hline
\end{tabular}

\section{Test family}

- 2 tailed $t$ test, Wilcoxon-Mann-Whitney test, Bonferroni's correction: alpha error $=0.008333$.

'Power calculations' performed with G*Power software, version 3.1.7 (Faul et al., 2007).

\section{Test family}

- Due to the large variance, these parametric tests are only used for comparison purposes. The sample size is based on the non-parametric tests listed above.

- Two-way ANOVA: Fixed effects, special, main effects and interactions: alpha error =0.05. 


\begin{tabular}{llllll} 
Group 1 & Group 2 & Effect size d & A priori power & Group 1 sample size & Group 2 sample size \\
\hline siLuc PTEN mRNA & siPTEN PTEN mRNA & 4.85884 & $96.8 \% *$ & $4^{*}$ & $4^{*}$ \\
\hline siLuc PTENP1 mRNA & siPTEN PTENP1 mRNA & 3.52537 & $93.1 \%$ & 5 & 5 \\
\hline siLuc PTEN mRNA & siPTENP1 PTEN mRNA & 3.32267 & $89.7 \%$ & 5 & 5 \\
\hline siLuc PTENP1 mRNA & siPTENP1 PTENP1 mRNA & 5.70745 & $83.9 \% \dagger$ & $3 \dagger$ & $3 \dagger$ \\
\hline siLuc PTEN mRNA & siPTEN/PTENP1 PTEN mRNA & 4.42658 & $93.2 \% \ddagger$ & $4 \ddagger$ & $4 \ddagger$ \\
\hline siLuc PTENP1 mRNA & siPTEN/PTENP1 PTENP1 mRNA & 3.27585 & $88.7 \%$ & 5 & 5
\end{tabular}

*5 samples per group will be used based on the siLuc to siPTENP1 PTEN comparison making the power $99.8 \%$. †5 samples per group will be used based on the siLuc to siPTENP1 PTEN comparison making the power $99.9 \%$. $\$ 5$ samples per group will be used based on the siLuc to siPTENP1 PTEN comparison making the power $99.3 \%$.

O Due to a lack of raw original data, we are unable to perform power calculations using a MANOVA. We are using a two-way ANOVA to estimate sample size.

Groups

SILUC, siPTEN, siPTENP1, siPTEN/ PTENP1 (PTEN and PTENP1 mRNA for all)

*40 total samples (5 per group) will be used based on the planned comparisons making the power $99.9 \%$.

'Power calculations' performed with G*Power software, version 3.1.7 (Faul et al., 2007).

ANOVA $F$ test statistic and partial $\eta^{2}$ performed with $R$ software, version 3.1.2 ( $R$ Development Core Team, 2014).

Test family

- Due to the large variance, these parametric tests are only used for comparison purposes. The sample size is based on the non-parametric tests listed above.

\begin{tabular}{|c|c|c|c|c|c|}
\hline Group 1 & Group 2 & Effect size $d$ & A priori power & Group 1 sample size & Group 2 sample size \\
\hline siLuc PTEN mRNA & SIPTEN PTEN mRNA & 4.85884 & $98.1 \% *$ & $4^{\star}$ & $4^{\star}$ \\
\hline siLuc PTENP1 mRNA & siPTEN PTENP1 mRNA & 3.52537 & $80.8 \% \dagger$ & $4 \dagger$ & $4 \dagger$ \\
\hline siLuc PTEN mRNA & siPTENP1 PTEN mRNA & 3.32267 & $92.2 \%$ & 5 & 5 \\
\hline siLuc PTENP1 mRNA & siPTENP1 PTENP1 mRNA & 5.70745 & $89.1 \% \ddagger$ & $3 \ddagger$ & $3 \ddagger$ \\
\hline siLuc PTEN mRNA & siPTEN/PTENP1 PTEN mRNA & 4.42658 & $95.4 \% \S$ & $4 \S$ & $4 \S$ \\
\hline siLuc PTENP1 mRNA & siPTEN/PTENP1 PTENP1 mRNA & 3.27585 & $91.4 \%$ & 5 & 5 \\
\hline
\end{tabular}

*5 samples per group will be used based on the siLuc to siPTENP1 PTEN comparison making the power $99.9 \%$.

†5 samples per group will be used based on the siLuc to siPTENP1 PTEN comparison making the power $95.1 \%$.

$\$ 5$ samples per group will be used based on the siLuc to siPTENP1 PTEN comparison making the power $99.9 \%$.

$\$ 5$ samples per group will be used based on the siLuc to siPTENP1 PTEN comparison making the power $99.6 \%$.

- 2 tailed $t$ test, difference between two independent means, Bonferroni's correction: alpha error = 0.008333.

\begin{tabular}{|c|c|}
\hline siRNA & Relative PTEN signal \\
\hline siLuc & 1.00 \\
\hline SiPTEN & 0.50 \\
\hline siPTENP1 & 0.60 \\
\hline siPTEN/PTENP1 & 0.10 \\
\hline
\end{tabular}




\section{Protocol 4}

Summary of original data reported in Figure $2 \mathrm{H}$ :

The original data do not indicate the error associated with multiple biological replicates. To identify a suitable sample size, power calculations were performed using different levels of relative variance.

Test family

- Two-way ANOVA: Fixed effects, special, main effects and interactions: alpha error =0.05.

'Power calculations' performed with G*Power software, version 3.1.7 (Faul et al., 2007).

ANOVA $F$ test statistic and partial $\eta^{2}$ performed with $R$ software, version 3.1.2 ( $R$ Development Core Team, 2014).

$2 \%$ variance:

\begin{tabular}{llllll} 
Groups & F test statistic & Partial $\eta^{2}$ & Effect size $\boldsymbol{f}$ A priori power & Total sample size \\
\hline siLUC, siPTEN, siPTENP1, siPTEN/ & $F(1,8)=4629.6$ (main effect: siPTEN) & 0.99828 & 24.0564 & $99.9 \%$ & $8(4$ groups) \\
\cline { 2 - 6 } \begin{tabular}{l} 
PTENP1 \\
\cline { 2 - 6 }
\end{tabular} & $F(1,8)=2963.0$ (main effect: siPTENP1) & 0.99731 & 19.24404 & $99.9 \%$ & $8(4$ groups) \\
\hline
\end{tabular}

$15 \%$ variance:

\begin{tabular}{llllll} 
Groups & F test statistic & Partial $\eta^{2}$ & Effect size $\mathbf{f}$ A priori power & Total sample size \\
\hline siLUC, siPTEN, siPTENP1, siPTEN/ & $F(1,8)=82.3050$ (main effect: siPTEN) & 0.91141 & 3.20750 & $99.9 \%$ & $8(4$ groups) \\
\cline { 2 - 6 } \begin{tabular}{l} 
PTENP1 \\
\cline { 2 - 6 }
\end{tabular} & $F(1,8)=52.6750$ (main effect: siPTENP1) & 0.86815 & 2.56600 & $99.9 \%$ & $8(4$ groups)
\end{tabular}

$28 \%$ variance:

\begin{tabular}{llllll} 
Groups & F test statistic & Partial $\eta^{2}$ & Effect size $\boldsymbol{f}$ A priori power Total sample size \\
\hline siLUC, siPTEN, siPTENP1, siPTEN/ & $F(1,8)=23.6210$ (main effect: siPTEN) & 0.74700 & 1.71830 & $94.5 \%$ & $8(4$ groups) \\
\cline { 2 - 6 } \begin{tabular}{l} 
PTENP1 \\
\cline { 2 - 6 }
\end{tabular} & $F(1,8)=15.1170$ (main effect: siPTENP1) & 0.65394 & 1.37464 & $82.4 \%$ & $8(4$ groups)
\end{tabular}

$40 \%$ variance:

\begin{tabular}{llllll} 
Groups & F test statistic & Partial $\eta^{2}$ & Effect size $\boldsymbol{f}$ A priori power Total sample size \\
\hline siLUC, siPTEN, siPTENP1, siPTEN/ & $F(1,8)=11.5741$ (main effect: siPTEN) & 0.59130 & 1.20281 & $95.3 \%$ & $12(4$ groups) \\
\cline { 2 - 6 } PTENP1 & $F(1,8)=7.4074$ (main effect: siPTENP1) & 0.48077 & 0.96225 & $83.0 \%$ & $12(4$ groups)
\end{tabular}

\section{Test family}

- 2 tailed $t$ test, difference between two independent means, Bonferroni's correction: alpha error $=0.01$.

'Power calculations' performed with G*Power software, version 3.1.7 (Faul et al., 2007). $2 \%$ variance:

\begin{tabular}{llllll} 
Group 1 & Group 2 & Effect size $d$ & A priori power & Group 1 sample size & Group 2 sample size \\
\hline siLuc & siPTEN & 39.28399 & $99.9 \%$ & 2 & 2 \\
\hline siLuc & siPTENP1 & 31.42719 & $99.9 \%$ & 2 & 2 \\
\hline siLuc & siPTEN/PTENP1 & 70.71118 & $99.9 \%$ & 2 & 2 \\
\hline siPTEN/PTENP1 & siPTEN & 31.42719 & $99.9 \%$ & 2 & 2 \\
\hline siPTEN/PTENP1 & siPTENP1 & 39.28399 & $99.9 \%$ & 2 & 2 \\
\hline
\end{tabular}

$15 \%$ variance:

\begin{tabular}{llllll}
\hline Group 1 & Group 2 & Effect size $d$ & A priori power & Group 1 sample size & Group 2 sample size \\
\hline siluc & siPTEN & 5.23782 & $86.6 \%$ & 3 & 3 \\
\hline
\end{tabular}

Continued on next page 
Continued

\begin{tabular}{llllll} 
Group 1 & Group 2 & Effect size d & A priori power & Group 1 sample size & Group 2 sample size \\
\hline siLuc & siPTENP1 & 4.19026 & $86.6 \%$ & 4 & 4 \\
\hline siLuc & siPTEN/PTENP1 & 9.42808 & $99.9 \%$ & 3 & 3 \\
\hline siPTEN/PTENP1 & siPTEN & 4.19026 & $94.6 \%$ & 4 & 4 \\
\hline siPTEN/PTENP1 & siPTENP1 & 5.23782 & $86.6 \%$ & 3 & 3
\end{tabular}

$28 \%$ variance:

\begin{tabular}{llllll} 
Group 1 & Group 2 & Effect size $d$ & A priori power & Group 1 sample size & Group 2 sample size \\
\hline siLuc & siPTEN & 2.80603 & $82.0 \%$ & 5 & 5 \\
\hline siLuc & siPTENP1 & 2.24482 & $84.8 \%$ & 7 & 7 \\
\hline siLuc & siPTEN/PTENP1 & 5.05085 & $84.0 \%$ & 3 & 3 \\
\hline siPTEN/PTENP1 & siPTEN & 2.24482 & $84.8 \%$ & 7 & 7 \\
\hline siPTEN/PTENP1 & siPTENP1 & 2.80603 & $82.0 \%$ & 5 & 5 \\
\hline
\end{tabular}

40\% variance:

\begin{tabular}{llllll} 
Group 1 & Group 2 & Effect size $d$ & A priori power & Group 1 sample size & Group 2 sample size \\
\hline siluc & siPTEN & 1.96419 & $86.9 \%$ & 8 & 8 \\
\hline siLuc & siPTENP1 & 1.57135 & $84.7 \%$ & 12 & 12 \\
\hline siLuc & siPTEN/PTENP1 & 3.53554 & $91.0 \%$ & 4 & 12 \\
\hline siPTEN/PTENP1 & siPTEN & 1.57135 & $83.6 \%$ & 8 & 12 \\
\hline siPTEN/PTENP1 & siPTENP1 & 1.96419 & $81.0 \%$ & 8
\end{tabular}

In order to produce quantitative replication data, we will run the experiment five times. Each time we will quantify band intensity. We will determine the standard deviation of band intensity across the biological replicates and combine this with the reported value from the original study to simulate the original effect size. We will use this simulated effect size to determine the number of replicates necessary to reach a power of at least $80 \%$. We will then perform additional replicates, if required, to ensure that the experiment has more than $80 \%$ power to detect the original effect.

\section{Protocol 5}

Summary of original data estimated from graph reported in Figure 4A, left panel:

\begin{tabular}{llll} 
Plasmid & Mean & Stdev & N \\
\hline pCMV & 1.000 & 0.541 & 3 \\
\hline pCMV/PTEN 3' UTR & 3.880 & 0.707 & 3 \\
\hline
\end{tabular}

\section{Test family}

- 2 tailed $t$ test, difference between two independent means, alpha error $=0.05$.

'Power calculations' performed with G*Power software, version 3.1.7 (Faul et al., 2007).

\begin{tabular}{llllll} 
Group 1 & Group 2 & Effect size d & A priori power & Group 1 sample size & Group 2 sample size \\
\hline pCMV & PCMV/PTEN 3' UTR & 4.57446 & $98.2 \%$ & 3 & 3
\end{tabular}

\section{Protocol 6}

Summary of original data estimated from graph reported in Figure 4A, right panel: 


\begin{tabular}{lllll} 
Plasmid & Day & Mean & Stdev & N \\
\hline pCMV & 0 & 1.000 & 0 & 3 \\
\cline { 2 - 5 } & 1 & 1.000 & 0.119 & 3 \\
\cline { 2 - 5 } & 2 & 1.238 & 0.119 & 3 \\
\cline { 2 - 5 } & 3 & 1.917 & 0.119 & 3 \\
\hline pCMV/PTEN 3' UTR & 4 & 5.726 & 0.119 & 3 \\
\cline { 2 - 5 } & 5 & 7.167 & 0.119 & 3 \\
\cline { 2 - 5 } & 0 & 1.000 & 0.119 & 3 \\
\hline & 1 & 1.000 & 0.119 & 3 \\
\hline & 2 & 1.143 & 0.119 & 3 \\
\hline & 3 & 1.917 & 0.214 & 3 \\
\hline
\end{tabular}

AUC calculations from estimated values.

Calculations performed with R software 3.1.2 (R Development Core Team, 2014).

\begin{tabular}{lllll} 
Plasmid & Days & Mean & Stdev & N \\
\hline pCMV & $0,1,2,3,4,5$ & 13.964 & 0.536 & 3 \\
\hline pCMV/PTEN 3' UTR & $0,1,2,3,4,5$ & 11.333 & 0.631 & 3
\end{tabular}

\section{Test family}

- 2 tailed $t$ test, difference between two independent means, alpha error $=0.05$.

'Power calculations' performed with G*Power software, version 3.1.7 (Faul et al., 2007).

Day 5 values

\begin{tabular}{llllll} 
Group 1 & Group 2 & Effect size $d$ & A priori power & Group 1 sample size & Group 2 sample size \\
\hline pCMV & PCMV/PTEN 3' UTR & 16.20000 & $99.9 \%$ & $2^{*}$ & $2^{\star}$
\end{tabular}

*3 samples per group will be used based on the AUC calculation.

\section{AUC values}

\begin{tabular}{llllll} 
Group 1 & Group 2 & Effect size $d$ & A priori power & Group 1 sample size & Group 2 sample size \\
\hline PCMV & PCMV/PTEN 3' UTR & 4.49526 & $97.9 \%$ & 3 & 3
\end{tabular}

\section{Acknowledgements}

The Reproducibility Project: Cancer Biology core team would like to thank the original authors, in particular Laura Poliseno, Leonardo Salmena, and Pier Paolo Pandolfi, for generously sharing critical information as well as reagents to ensure the fidelity and quality of this replication attempt. We thank Courtney Soderberg at the Center for Open Science for assistance with statistical analyses. We would also like to thank the following companies for generously donating reagents to the Reproducibility Project: Cancer Biology; American Type Culture Collection (ATCC), Applied Biological Materials, BioLegend, Charles River Laboratories, Corning Incorporated, DDC Medical, EMD Millipore, Harlan Laboratories, LI-COR Biosciences, Mirus Bio, Novus Biologicals, Sigma-Aldrich, and System Biosciences (SBI). We thank Dale Cowley and Kumar Pandya, TransViragen, Inc., for technical suggestions related to experiments to be performed. 


\section{Additional information}

Group author details

Reproducibility Project: Cancer Biology

Elizabeth lorns: Science Exchange, Palo Alto, California; William Gunn: Mendeley, London, United Kingdom; Fraser Tan: Science Exchange, Palo Alto, California; Joelle Lomax: Science Exchange, Palo Alto, California; Nicole Perfito: Science Exchange, Palo Alto, California; Timothy Errington: Center for Open Science, Charlottesville, Virginia

Competing interests

IK: Alamo Laboratories Inc. is a Science Exchange associated laboratory. JK: Biotechnology Research and Education Program, University of Maryland is a Science Exchange associated laboratory. RP:CB: EI, FT, JL, and NP are employed and holds shares in Science Exchange Inc. The other authors declare that no competing interests exist.

Funding

Funder

Author

Laura and John Arnold

foundation

Reproducibility Project: Cancer

The Reproducibility Project: Cancer Biology is funded by the Laura and John Arnold Foundation, provided to the Center for Open Science in collaboration with Science Exchange. The funder had no role in study design or the decision to submit the work for publication.

Author contributions

IK, JK, KO, EG, Drafting or revising the article; RP:CB, Conception and design, Drafting or revising the article

\section{References}

Bauer TM, Patel MR, Infante JR. 2014. Targeting PI3 kinase in cancer. Pharmacology \& Therapeutics 146:53-60. doi: 10.1016/j.pharmthera.2014.09.006.

Broderick JA, Zamore PD. 2014. Competitive endogenous RNAs cannot alter microRNA function in vivo. Molecular Cell 54:711-713. doi: 10.1016/j.molcel.2014.05.023.

Carracedo A, Salmena L, Pandolfi PP. 2008. SnapShot: PTEN signaling pathways. Cell 133:550.e1. doi: 10.1016/j. cell.2008.04.023.

Cesana M, Daley GQ. 2013. Deciphering the rules of ceRNA networks. Proceedings of the National Academy of Sciences of USA 110:7112-7113. doi: 10.1073/pnas.1305322110.

Chan JA, Krichevsky AM, Kosik KS. 2005. MicroRNA-21 is an antiapoptotic factor in human glioblastoma cells. Cancer Research 65:6029-6033. doi: 10.1158/0008-5472.CAN-05-0137.

Chen CL, Tseng YW, Wu JC, Chen GY, Lin KC, Hwang SM, Hu YC. 2015. Suppression of hepatocellular carcinoma by baculovirus-mediated expression of long non-coding RNA PTENP1 and MicroRNA regulation. Biomaterials 44:71-81. doi: 10.1016/j.biomaterials.2014.12.023.

Chen H, Mei L, Zhou L, Shen X, Guo C, Zheng Y, Zhu H, Zhu Y, Huang L. 2011. PTEN restoration and PIK3CB knockdown synergistically suppress glioblastoma growth in vitro and in xenografts. Journal of Neuro-Oncology 104:155-167. doi: 10.1007/s11060-010-0492-2.

Denzler R, Agarwal V, Stefano J, Bartel DP, Stoffel M. 2014. Assessing the ceRNA hypothesis with quantitative measurements of miRNA and target abundance. Molecular Cell 54:766-776. doi: 10.1016/j.molcel.2014. 03.045 .

Errington TM, lorns E, Gunn W, Tan FE, Lomax J, Nosek BA. 2014. An open investigation of the reproducibility of cancer biology research. eLife 3:e04333. doi: 10.7554/eLife.04333.

Faul F, Erdfelder E, Lang AG, Buchner A. 2007. G*Power 3: a flexible statistical power analysis program for the social, behavioral, and biomedical sciences. Behavior Research Methods 39:175-191. doi: 10.3758/BF03193146.

Franco-Zorrilla JM, Valli A, Todesco M, Mateos I, Puga MI, Rubio-Somoza I, Leyva A, Weigel D, Garcia JA, PazAres J. 2007. Target mimicry provides a new mechanism for regulation of microRNA activity. Nature Genetics 39: 1033-1037. doi: 10.1038/ng2079.

Fujii GH, Morimoto AM, Berson AE, Bolen JB. 1999. Transcriptional analysis of the PTEN/MMAC1 pseudogene, psiPTEN. Oncogene 18:1765-1769. doi: 10.1038/sj.onc.1202492.

Fullwood MJ, Liu MH, Pan YF, Liu J, Xu H, Mohamed YB, Orlov YL, Velkov S, Ho A, Mei PH, Chew EG, Huang PY, Welboren WJ, Han Y, Ooi HS, Ariyaratne PN, Vega VB, Luo Y, Tan PY, Choy PY, Wansa KD, Zhao B, Lim KS, Leow SC, Yow JS, Joseph R, Li H, Desai KV, Thomsen JS, Lee YK, Karuturi RK, Herve T, Bourque G, Stunnenberg HG, 
Ruan X, Cacheux-Rataboul V, Sung WK, Liu ET, Wei CL, Cheung E, Ruan Y. 2009. An oestrogen-receptor-alphabound human chromatin interactome. Nature 462:58-64. doi: 10.1038/nature08497.

Gerlinger M, Rowan AJ, Horswell S, Larkin J, Endesfelder D, Gronroos E, Martinez P, Matthews N, Stewart A, Tarpey P, Varela I, Phillimore B, Begum S, McDonald NQ, Butler A, Jones D, Raine K, Latimer C, Santos CR, Nohadani M, Eklund AC, Spencer-Dene B, Clark G, Pickering L, Stamp G, Gore M, Szallasi Z, Downward J, Futreal PA, Swanton C. 2012. Intratumor heterogeneity and branched evolution revealed by multiregion sequencing. The New England Journal of Medicine 366:883-892. doi: 10.1056/ NEJMoa1113205.

Guo X, Deng L, Deng K, Wang H, Shan T, Zhou H, Liang Z, Xia J, Li C. 2015. Pseudogene PTENP1 suppresses gastric cancer progression by modulating PTEN. Anti-Cancer Agents in Medicinal Chemistry.

Hopkins BD, Parsons RE. 2014. Molecular pathways: intercellular PTEN and the potential of PTEN restoration therapy. Clinical Cancer Research 20:5379-5383. doi: 10.1158/1078-0432.CCR-13-2661.

Jackson BL, Grabowska A, Ratan HL. 2014. MicroRNA in prostate cancer: functional importance and potential as circulating biomarkers. BMC Cancer 14:930. doi: 10.1186/1471-2407-14-930.

Johnsson P, Ackley A, Vidarsdottir L, Lui WO, Corcoran M, Grander D, Morris KV. 2013. A pseudogene longnoncoding-RNA network regulates PTEN transcription and translation in human cells. Nat Struct Mol Biol 20: 440-446. doi: 10.1038/nsmb.2516.

Karreth FA, Tay Y, Perna D, Ala U, Tan SM, Rust AG, DeNicola G, Webster KA, Weiss D, Perez-Mancera PA, Krauthammer M, Halaban R, Provero P, Adams DJ, Tuveson DA, Pandolfi PP. 2011. In vivo identification of tumor- suppressive PTEN ceRNAs in an oncogenic BRAF-induced mouse model of melanoma. Cell 147:382-395. doi: 10.1016/j.cell.2011.09.032.

Lee DY, Jeyapalan Z, Fang L, Yang J, Zhang Y, Yee AY, Li M, Du WW, Shatseva T, Yang BB. 2010. Expression of versican 3'-untranslated region modulates endogenous microRNA functions. PLOS ONE 5:e13599. doi: 10.1371/ journal.pone.0013599.

Li J, Simpson L, Takahashi M, Miliaresis C, Myers MP, Tonks N, Parsons R. 1998. The PTEN/MMAC1 tumor suppressor induces cell death that is rescued by the AKT/protein kinase B oncogene. Cancer Research $\mathbf{5 8}$ : 5667-5672.

Lu Y, Lin YZ, LaPushin R, Cuevas B, Fang X, Yu SX, Davies MA, Khan H, Furui T, Mao M, Zinner R, Hung MC, Steck P, Siminovitch K, Mills GB. 1999. The PTEN/MMAC1/TEP tumor suppressor gene decreases cell growth and induces apoptosis and anoikis in breast cancer cells. Oncogene 18:7034-7045. doi: 10.1038/sj.onc.1203183.

Luo X, Dong Z, Chen Y, Yang L, Lai D. 2013. Enrichment of ovarian cancer stem-like cells is associated with epithelial to mesenchymal transition through an miRNA-activated AKT pathway. Cell Proliferation 46:436-446. doi: 10.1111/cpr.12038.

Meng F, Henson R, Lang M, Wehbe H, Maheshwari S, Mendell JT, Jiang J, Schmittgen TD, Patel T. 2006. Involvement of human micro-RNA in growth and response to chemotherapy in human cholangiocarcinoma cell lines. Gastroenterology 130:2113-2129. doi: 10.1053/j.gastro.2006.02.057.

Meng F, Henson R, Wehbe-Janek H, Ghoshal K, Jacob ST, Patel T. 2007. MicroRNA-21 regulates expression of the PTEN tumor suppressor gene in human hepatocellular cancer. Gastroenterology 133:647-658. doi: 10.1053/j. gastro.2007.05.022.

Phin S, Moore MW, Cotter PD. 2013. Genomic rearrangements of PTEN in prostate Cancer. Frontiers in Oncology 3:240. doi: 10.3389/fonc.2013.00240.

Poliseno L, Salmena L, Zhang J, Carver B, Haveman WJ, Pandolfi PP. 2010. A coding-independent function of gene and pseudogene mRNAs regulates tumour biology. Nature 465:1033-1038. doi: 10.1038/nature09144.

Salmena L, Poliseno L, Tay Y, Kats L, Pandolfi PP. 2011. A ceRNA hypothesis: the Rosetta Stone of a hidden RNA language? Cell 146:353-358. doi: 10.1016/j.cell.2011.07.014.

Sen R, Ghosal S, Das S, Balti S, Chakrabarti J. 2014. Competing endogenous RNA: the key to posttranscriptional regulation. Thescientificworldjournal 2014:896206. doi: 10.1155/2014/896206.

Si ML, Zhu S, Wu H, Lu Z, Wu F, Mo YY. 2007. miR-21-mediated tumor growth. Oncogene 26:2799-2803. doi: 10. 1038/sj.onc.1210083.

Song MS, Salmena L, Pandolfi PP. 2012. The functions and regulation of the PTEN tumour suppressor. Nature Reviews. Molecular Cell Biology 13:283-296. doi: 10.1038/nrm3330.

Stambolic V, Suzuki A, de la Pompa JL, Brothers GM, Mirtsos C, Sasaki T, Ruland J, Penninger JM, Siderovski DP, Mak TW. 1998. Negative regulation of PKB/Akt-dependent cell survival by the tumor suppressor PTEN. Cell 95 : 29-39. doi: 10.1016/S0092-8674(00)81780-8.

Sumazin P, Yang X, Chiu HS, Chung WJ, lyer A, Llobet-Navas D, Rajbhandari P, Bansal M, Guarnieri P, Silva J, Califano A. 2011. An extensive microRNA-mediated network of RNA-RNA interactions regulates established oncogenic pathways in glioblastoma. Cell 147:370-381. doi: 10.1016/j.cell.2011.09.041.

Tay Y, Kats L, Salmena L, Weiss D, Tan SM, Ala U, Karreth F, Poliseno L, Provero P, Di Cunto F, Lieberman J, Rigoutsos I, Pandolfi PP. 2011. Coding-independent regulation of the tumor suppressor PTEN by competing endogenous mRNAs. Cell 147:344-357. doi: 10.1016/j.cell.2011.09.029.

R Development Core Team. 2014. R: A language and environment for statistical computing. R Foundation for Statistical Computing. http://www.R-project.org/.

Tian L, Fang YX, Xue JL, Chen JZ. 2013. Four microRNAs promote prostate cell proliferation with regulation of PTEN and its downstream signals in vitro. PLOS ONE 8:e75885. doi: 10.1371/journal.pone.0075885.

Tian XX, Pang JC, To SS, Ng HK. 1999. Restoration of wild-type PTEN expression leads to apoptosis, induces differentiation, and reduces telomerase activity in human glioma cells. Journal of Neuropathology and Experimental Neurology 58:472-479. doi: 10.1097/00005072-199905000-00006. 
Trotman LC, Niki M, Dotan ZA, Koutcher JA, Di Cristofano A, Xiao A, Khoo AS, Roy-Burman P, Greenberg NM, Van Dyke T, Cordon-Cardo C, Pandolfi PP. 2003. Pten dose dictates cancer progression in the prostate. PLOS Biology 1:E59. doi: 10.1371/journal.pbio.0000059.

Volinia S, Calin GA, Liu CG, Ambs S, Cimmino A, Petrocca F, Visone R, lorio M, Roldo C, Ferracin M, Prueitt RL, Yanaihara N, Lanza G, Scarpa A, Vecchione A, Negrini M, Harris CC, Croce CM. 2006. A microRNA expression signature of human solid tumors defines cancer gene targets. Proceedings of the National Academy of Sciences of USA 103:2257-2261. doi: 10.1073/pnas.0510565103.

Wang J, Du Y, Liu X, Cho WC, Yang Y. 2015. MicroRNAs as regulator of signaling networks in metastatic colon cancer. Biomed Research International 2015:823620. doi: 10.1155/2015/823620.

Wu TY, Zhang TH, Qu LM, Feng JP, Tian LL, Zhang BH, Li DD, Sun YN, Liu M. 2014. MiR-19a is correlated with prognosis and apoptosis of laryngeal squamous cell carcinoma by regulating TIMP-2 expression. International Journal of Clinical and Experimental Pathology 7:56-63.

Yu G, Yao W, Gumireddy K, Li A, Wang J, Xiao W, Chen K, Xiao H, Li H, Tang K, Ye Z, Huang Q, Xu H. 2014. Pseudogene PTENP1 functions as a competing endogenous RNA to suppress clear-cell renal cell carcinoma progression. Molecular Cancer Therapeutics 13:3086-3097. doi: 10.1158/1535-7163.MCT-14-0245. 